Final Report, 10/12/2012

\author{
DE-SC0007942
}

\title{
Participant Support for Speakers and Early-Career Scientists at the 2012 American Conference on Neutron Scattering (ACNS)
}

\author{
Butch Dillen \\ Director of Finance and Administration, Materials Research Society, \\ 506 Keystone Dr \\ Warrendale PA 15086-7573 \\ Tel: 724-779-2711 Fax: 724-779-8313 email: dillen@mrs.org

\section{Chris Leighton} \\ Secretary, Neutron Scattering Society of America, \\ Dept. of Chemical Engineering and Materials Science, \\ University of Minnesota, \\ 151 Amundson Hall, 421 Washington Ave SE, \\ Minneapolis, MN 55455
}

Tel: 612625 4018, Fax: 612626 7246, email: leighton@umn.edu

\section{ACNS Organizing Committee}

Julie Borchers, Chair

Bruce Gaulin, NSSA President

Stephan Rosenkranz, Program Co-chair

Nitash Balsara, Program Co-chair

Susan Krueger, Chair, Local Organizing Committee

\section{NSSA Executive Committee}

Bruce Gaulin, President Julie Borchers, Vice President John Tranquada, Treasurer Chris Leighton, Secretary Jaime Fernandez-Baca, Membership Sec. Thomas Proffen, Communications Sec. 


\section{Final Report: Participant Support for Speakers and Early-Career SCientists at the 2012 American Conference on NeUtron SCATtERING}

\section{EXECUTIVE SUMMARY}

The ACNS 2012 conference took place as scheduled from June $24^{\text {th }}$ through $28^{\text {th }}$ at the Georgetown University Conference Center, organized under the auspices of the Neutron Scattering Society of America (NSSA), in collaboration with the Materials Research Society (MRS). As discussed in detail below, we believe that, by all metrics, the conference was a resounding success. The meeting was focused around a vibrant and diverse program, highlighting both the depth and breadth of the remarkable scientific research being performed in the arena of neutron science in North America. In all, 378 registered attendees were attracted to this $6^{\text {th }}$ conference in the series (an increase of well over $30 \%$ in comparison to ACNS 2010), presenting 173 scientific talks and 138 posters. Of most direct relevance to this report the $\$ 25,000$ award provided by DOE (DE-SC0007942) enabled the conference organizers to waive registration fees for invited speakers (of which there were 38) and students, in addition to providing partial support for travel grants to 105 students and early-career researchers. The meeting served as a focal point for neutron-based research in North America, as a "super user meeting" of sorts, as a first-rate educational opportunity for young scientists, and as a tool both to strengthen the base of existing neutron users and to attract new users to US neutron facilities. Additional details on the activities and accomplishments are provided below.

\section{ACCOMPLISHMENTS AND ACTIVITIES: At-A-GLANCE}

The ACNS 2012 meeting highlights included:

- 378 registered attendees

- Over 100 student and post-doc attendees

- 173 oral presentations

- 38 invited speakers

- 138 poster presentations

- 326 abstract submissions

- 276 unique contributions

- 7 paid exhibitors

- 2 tutorials

- 3 plenary sessions

- 4 prize acceptance talks

- A well-attended conference banquet featuring 2 speakers

- Daily poster sessions and vendor exhibits

\section{Conference Organization}

The organization of the ACNS 2012 conference proceeded as anticipated, and as laid out in detail in the proposal for this award. The overall structure of the organization and program are shown in Figures 1 and 2, for reference.

\section{ACCOMPLISHMENTS AND ACtivities: Detailed RePORT}

The conference began with popular tutorial sessions on "Advances in Time-of-flight Neutron Powder Diffraction" and "Novel Techniques for Small-Angle Neutron Scattering Techniques", chaired by Thomas Proffen (Oak Ridge National Lab) and Kathryn Krycka (NIST), respectively. In addition to the regular oral and poster sessions the conference also included a series of plenary sessions featuring plenary presentations, and prize acceptance presentations. Non-technical plenary talks were presented by Altaf Carim from OSTP, and by Yasuhiko Fujii on behalf of AONSA (The Asia-Oceania Neutron Scattering Association). The former focused on federal 
science and technology policy and the 2013 budget, while the latter, a reciprocal invitation by NSSA from the earlier AONSA meeting, provided an overview of exciting neutron science developments in Asia and Oceania. Potential for collaboration with the North American scattering community was covered in some detail. Fascinating scientific plenary talks were provided by Tim Lodge of the University of Minnesota and Leon Balents of the University of California Santa Barbara, on block copolymer miscelles and

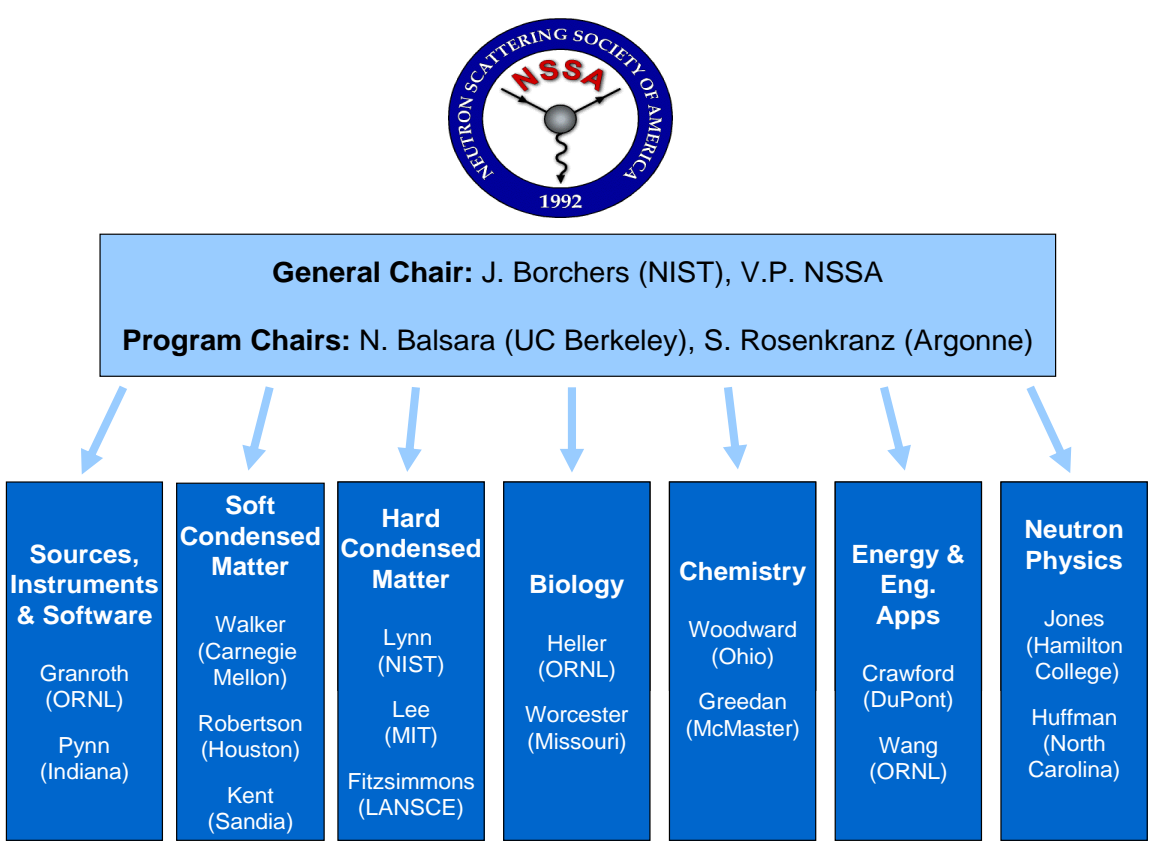

Fig. 1. Organizational structure of ACNS 2012 quantum spin liquids, respectively. Prize acceptance talks by the winners of the four main NSSA prizes made up the remainder of the plenary sessions. These were presented by Guangyong $\mathrm{Xu}$, Robert Birgeneau, Suzanne te Velthuis (on behalf of Gian Felcher), and Claire White, the recipients of the Science, Shull, Sustained Research, and Student Prizes. The plenary sessions also enabled the NSSA to briefly recognize the members of the organization elected to Fellow in 2012 (Julie Borchers, Robert Cava, Charles Glinka, Eric Kaler, Roger Pynn, Steven Shapiro, Gregory Smith, Haskell Taub, and Samuel Werner).

The main scientific sessions took place over the course of a three-day program, featuring 32 oral sessions and 3 poster sessions (see Figure 3), with 173 talks and 138 posters. These
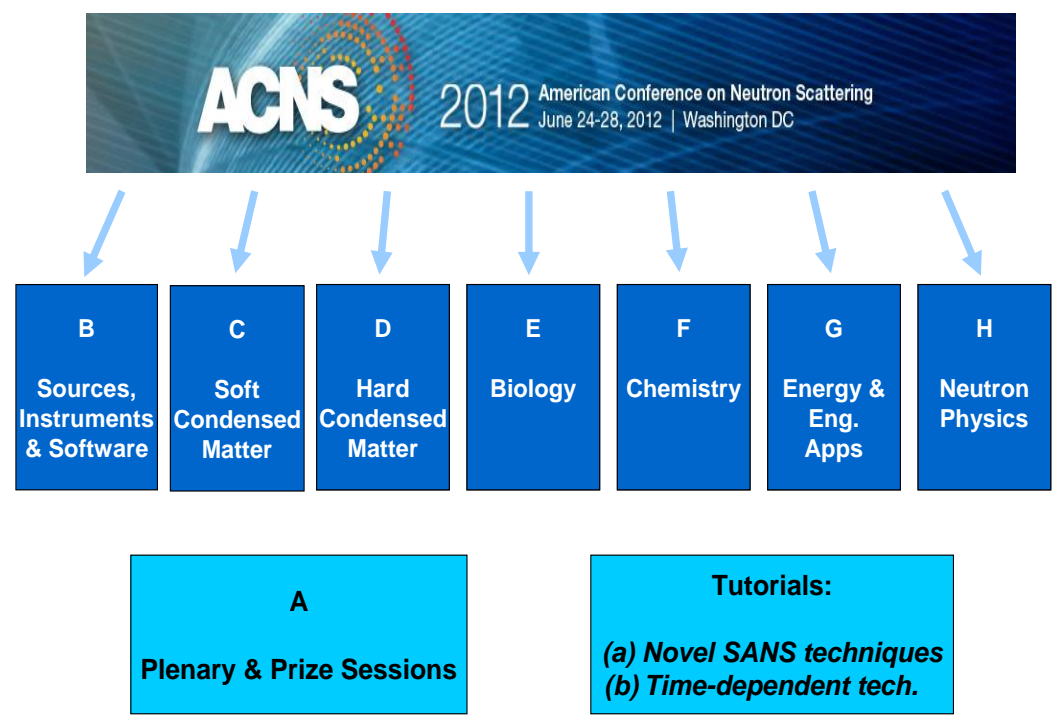

Fig. 2. Overall structure of the ACNS 2012 program sessions reflected the extraordinary breadth of neutron-based research in the US, covering topics as diverse as neutron instrumentation and methods, superconductivity, magnetism, mechanical properties of materials, biomembranes, zeolite materials, polymers, nanomaterials, energy materials, proteins, and fundamental neutron physics. In all, 378 registered attendees contributed to 276 unique contributions to the meeting, numbers that reflect substantial increases over 2010 levels. Of particular importance to this award, the NSSA/ACNS efforts 
to increase participation of students and other early-career scientists was successful, leading to well over 100 student and post-doc attendees and 105 travel awards to offset attendance costs for young researchers.

The conference banquet also featured a pair of informative and entertaining presentations by Robert Shull (focusing on recollections of Cliff Shull's Nobel Prize winning work on neutron scattering) and Samuel Werner (recalling the founding of the NSSA 20 years earlier). Finally, the conference concluded on the final day with a tour of the newly completed guide-hall at the NIST Center for Neutron Research for all interested conference participants.

\section{SUPPLEMENTARY INFORMATION} The front matter from the ACNS 2012 program book is attached here in lieu of a formal conference proceedings volume.

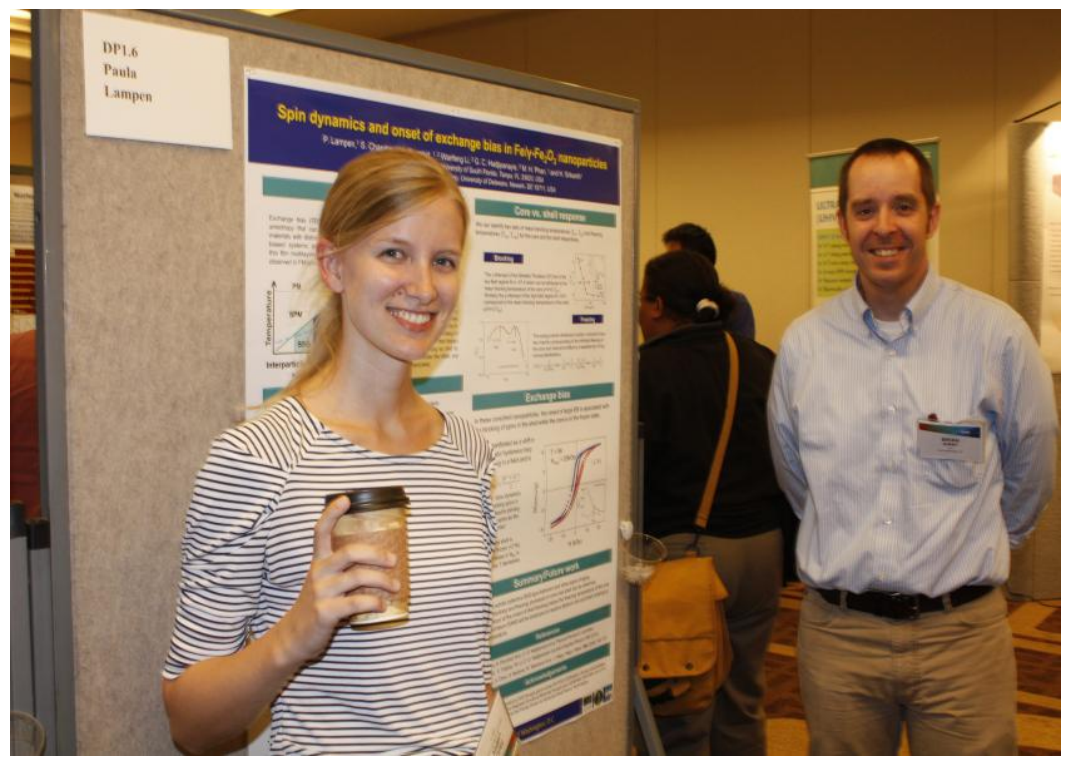

Fig. 3. Student attendee Paula Lampen of the University of South Florida discussing her presentation with Brian Kirby of NIST at an ACNS 2012 poster session. We also attach a copy of the report written by C. Majkrzak and J. Borchers for the Taylor and Francis Neutron News publication, circulated to all subscribers in addition to all NSSA members.

\section{CONCLUSION AND SUMmarY}

In short, the DOE award of a $\$ 25,000$ grant played a significant role in establishing ACNS 2012 as a remarkably successful $6^{\text {th }}$ in the series of ACNS conferences. The award enabled waiving of the registration fees for 28 invited speakers, in addition to supporting travel costs for over 100 early-career scientists. The ACNS series remains a well-attended and vibrant meeting serving multiple important functions for the US neutron science community. 


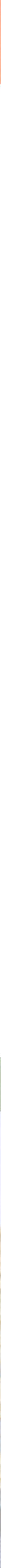


Conference Highlights

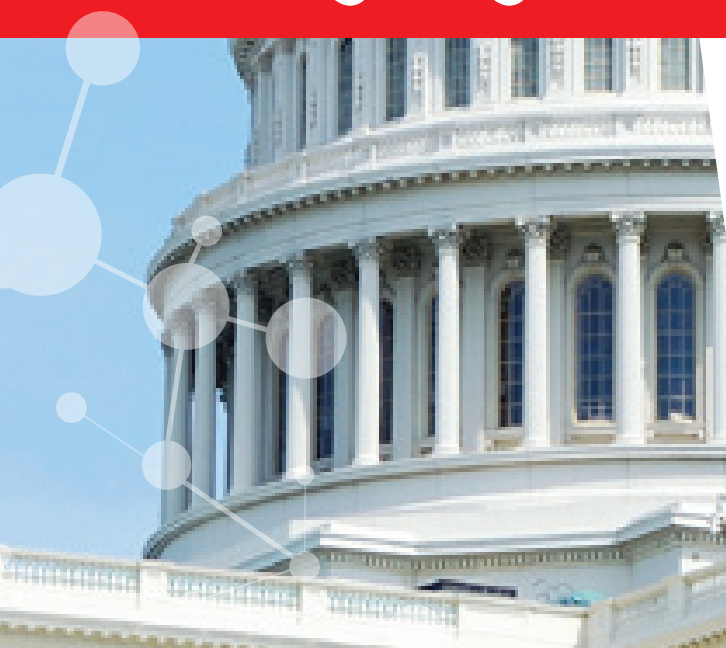

Special Presentations
ABOUT ACNS 2012

Scientists from 16 countries will converge in Washington, DC this week for the
2012 American Conference on Neutron Scattering. Sponsored by the Neutro Scattering Society of America and hosted by NIST Center for Neutron Research, the conference features over 325 oral and poster presentations. A strong program of plenary, invited and contributed talks and poster sessions cover topics in engineering applications and neutron physics-confirming the great diversity of science that is enabled by neutron scattering.

TUTORIALS

Start the Conference off on Sunday afternoon with two tutorials free to conference Novel Techniques for Small Angle Neutron Scattering. For more details, see page 10.

WELCOME RECEPTION

Conference attendees are invited to the Welcome Reception on Sunday evening Conference registration fee.

POSTER SESSIONS/RECEPTIONS

Authors are available for in-depth discussions of their research during the Poster 6essions and Receptions held in Room $\mathrm{C} / \mathrm{F} / \mathrm{H}$ Monday and Wednesday from are open to all registered Conference attendees. Complimentary refreshments

COMPANION TICKET Guests/companions accompanying you to the Conference may purchase
Companion Tickets for $\$ 00$ per person. Tickets grant admission to the Welcome EXHIBIT

Be sure to visit the ACNS exhibitors Sunday through Wednesday, in Room C/F/H.

Be sure to visit the ACNS exhibitors Sunday through Wednesday, in Room C/F/H
Learn more about the latest products and services in the ravidly evolving world of
neutron scattering. See daily Schedule of Events for times.

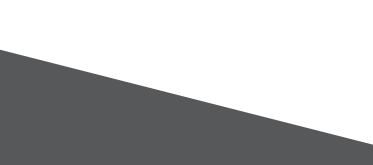

MONDAY, JUNE 25 Room G

TUESDAY, JUNE 26 Room G

PLENARY

8:30 am $-9: 00$ am
Altaf H. Carim

Aftice of Sacim
Execentive and Tectice of the Presiogy Policy

Federal Sciennee and Technology Policy, Initiatives,
and Budget for Fiscal Year 2013

SCIENCE PRIZE WINNER

9:00 am - 9:30 am
Guangyong xu
Brookheven Nation

Probing Local Polar Structures in PRN-xPT and PMN-xPT Relaxor
Ferroelectrics using Neutron and X-Ray Scattering

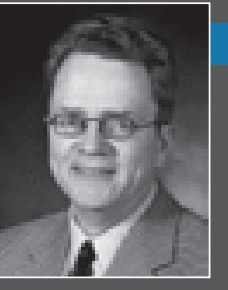

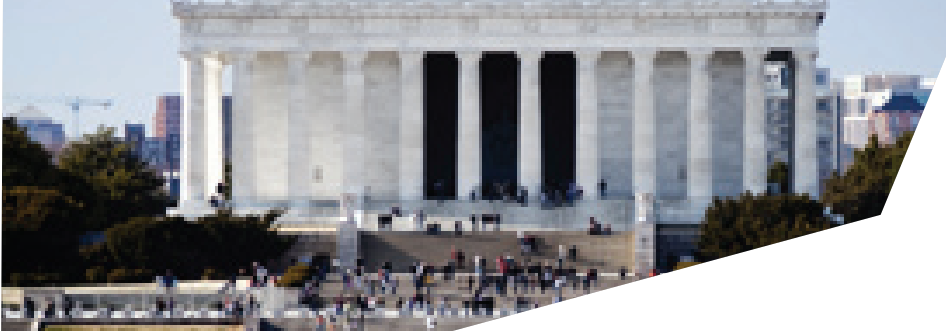

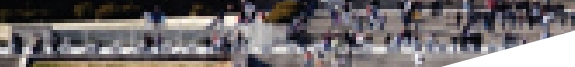

\section{menas}

NSSA PRIZE CEREMONY

Tuesday morning brings special honors to four recipients. Robert $J$. Shull Prize; Gian Piero Felcher, Argonne National Laboratory, receives the Sustained Research Prize; Guangyong Xu, Brookhaven Nationa National Laboratory, receives the inaugural Prize for Outstanding Student Research. Join us at 8:15 am in Room G for this momentous occasion.

CONFERENCE BANQUET

Don't miss this year's Conference Banquet-Tuesday evening at 7:00 pm
in Room G G-featuring talks from leading experts in the field. Robert $D$. Shull, National Institute of Standards and Technology, will present his talk: AMemoir of Cilford G. Shul, Neutson Scatlering at the Beginning, and

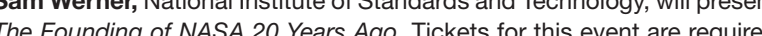

and may be purchased at registration for $\$ 75.00$ per person. Admission

the Banquet is not included in conference egistar
9::30 am - 10:00 am
Timothy Lodge

The Conference culminates on Thursday with a free tour of the NIST
facilities in Gaithersburrg Manyland Advance registration was reguired. See Registration Desk for bus times and location.

EXPERIENCE THE NATION'S CAPTAL-WASHINGTON, DC Georgetown, situated on the bluffs of Washington, $D C$, is rich in history and
culture, making it an ideal conference and vacation destination Known for its high-end shopping and dining and quaint row houses overlooking Waterfront Harbor, Georgetown is truly unlike any other city in the U.S. Take Walk back in time on the famous 18 hilh century cobblestone streets. Vist John Calhoun Add in all the sites and attractions found in nearby Washington DC, and you'll never have a dull moment

SAVE THE DATE!

The 2013 International Conference on Neutron Scattering (ICNS 2013
will be held in Edinburgh, UK. July 8-12, 2013. Mark your calendar tody! 
NSSA EXECUTIVE COMMITTEE

Bruce D. Gaulin McMaster University

Julie Borchers NIST Center for Neutron Research

Chris Leighton University of Minnesota

Membership Secretary Jaime A. Fernandez-Baca Oak Ridge National Laboratory

Communications Secretary Thomas Proffen Oak Ridge National Laboratory

ORGANIZING COMMITTEE

Conference Chair Julie Borchers NIST Center for Neutron Research NSSA President Bruce D. Gaulin McMaster University

\section{PROGRAM COMMITTEE}

Co-Chair Nitash Balsara University of California, Berkeley

Co-Chair Stephan Rosenkranz Argonne National Laboratory

A: Plenary \& Prize Sessions

Stephan Rosenkranz Argonne National Laboratory
Nitash Balsara University of California, Berkeley

B: Sources, Instrumentation \& Software

Garrett Granroth Oak Ridge National Laboratorn

Roger Pynn Indiana University

C: Soft Condensed Matter
Lynn Walker Carnegie Mellon University

Megan Robertson University of Houston

D.

D: Hard Condensed Matter

Jeff Lynn National Institute of Standards and Technology

Young Lee Massachusetts Institute of Technology
Michael Fitzsimmons Los Alamos National Laboratory

E: Biology

E: Biology
William Heller Oak Ridge National Laboratory
David Worcester University of Missouri, Columbia

F. Chemistry

F: Chemistry
Patrick Woodward Ohio State University

John Greedan McMaster University

G: Energy \& Engineering Applications

Mike Crawford Du Pont

Xun-Li Wang Oak Ridge National Laboratory

H: Neutron Physics

Gordon Jones Hamilton College

LOCAL ORGANIZING COMMITTEE

Chair Susan Krueger NIST Center for Neutron Research Tanya Burke NIST Center for Neutron Research Peter Gehring NIST Center for Neutron Research Yamali Hernandez NIST Center for Neutron Research Steve Kline NIST Center for Neutron Research Kaye Rubinson Georgetown Un Niversity Sarah Stoll Georgetown University Richard Weiss Georgetown University

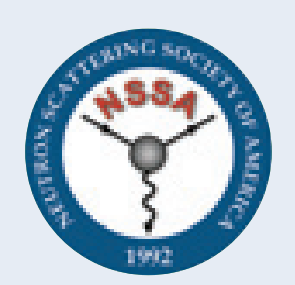

The Neutron Scattering Society of America (NSSA in neutron scattering research in a wide spectrum of disciplines from materials science to physics, chemistry to biochemistry. The NSSA was formed in 1992 to provide a forum for the discussion of scientifici issues, major facilities and instrumentation needs for world-class neutron scattering research in North America. The main goal of the Society is to stimulare, promote and broaden the use of neutron Membership in the Society is available at no cost to individuals in academia, industry and government. Graduate students and recent Ph.D.s are especially encouraged to join. Presently the NSSA has more

We encourage all conference attendees to stop by the NSSA booth during the ACNS conference, or visit www.neutronscattering.org.

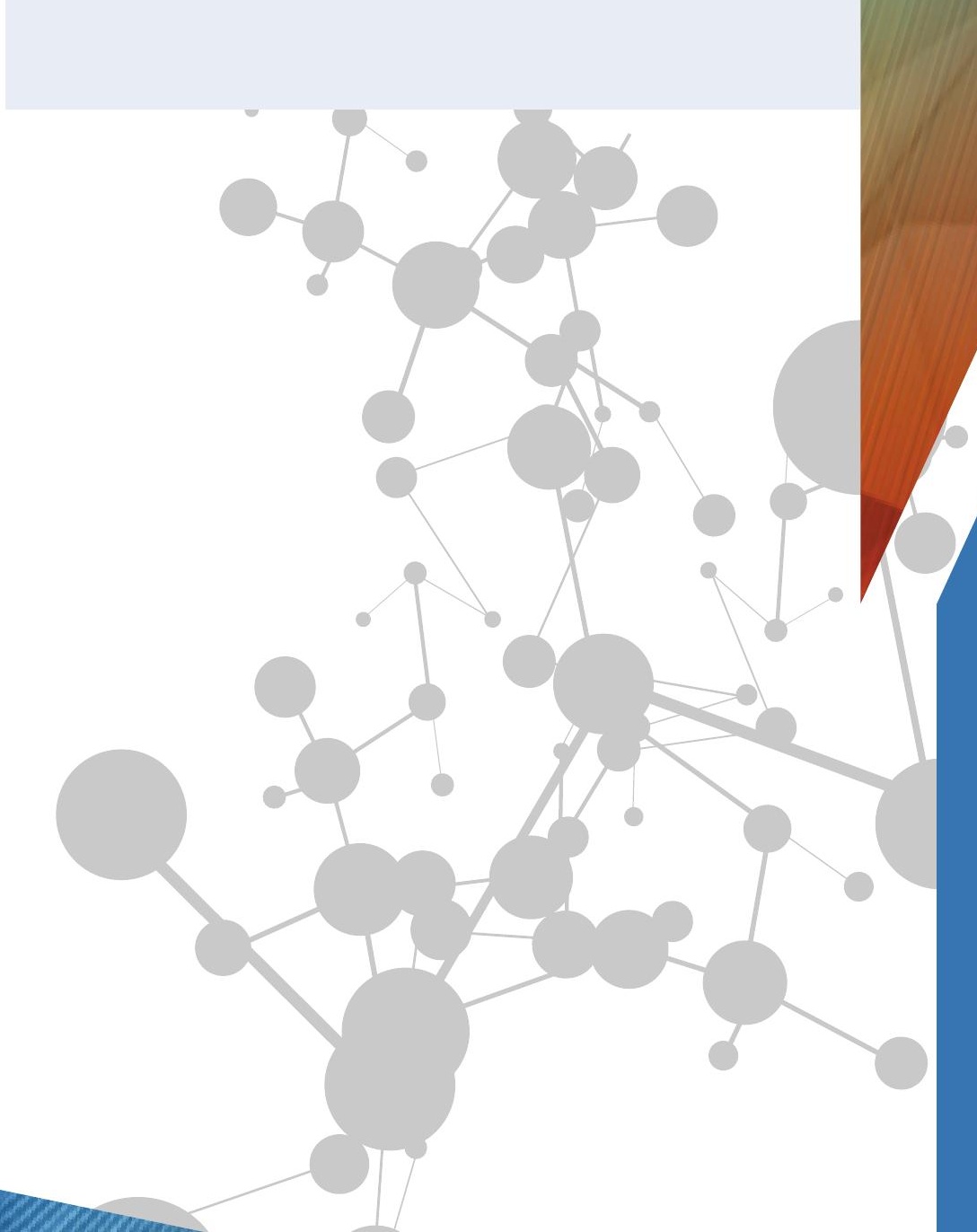

The Neutron Scattering Society of America is pleased to announce the 2012 Fellows of the Society.

TUESDAY, JUNE 26

9:15 am | Room G

Julie Borchers NIST Center for Neutron Research For insightful neutron investigations of magnetic materials, particularly interlayer exchange
interactions phenomena in magnetic thin films and superlattices Robert Cava Princeton University For outstanding applications of neutron diffraction to the understanding of complex materials,
and advocacy for the field particularly among young scientists Charles Glinka University of Delaware and National Institute of Standards and Technology For development and operation of world-class capabilities for small angle neurron scathering
in America

Eric Kaler University of Minnesota

Roger Pynn University of Indianı

\section{For outstanding contributions to neutron scatte
and for service to the U.S. neutron community}

Steven Shapiro Brookhaven National Laboratory

Gregory Smith Oak Ridge National Laboratory

For pioneering neutron scettering investigetions of soft-conclinged neter yystems

Haskell Taub University of Missouri For sustained studies of the structure, phase transitions, and dynamics of adsorbed films using

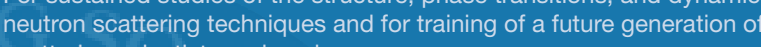

Samuel Werner National Institute of Standards and Technology

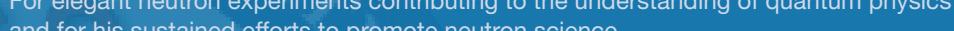

Through the NSSA Fellowship Program, the NSSA recognizes members who have made significant contributions to the neutron scattering community in North America in one or more of the following areas: advances in knowledge through original research and publication; innovative contributions
in the application of neutron scattering; contributions to the promotion or development of neutron scattering techniques; and service and participation in the activities of the NSSA or neutron limited to no more than one half of one percent of the membership. Additionally, recipients of istanding contributions to neutron scattering and the North American neutron scattering community. 
The Neutron Scattering Society of America is pleased to announce the 2012 recipients of its four major prizes.

PRIZE CEREMONY | TUESDAY, JUNE 26
$8: 15$ am | ROOm G 8:15 am | Room G

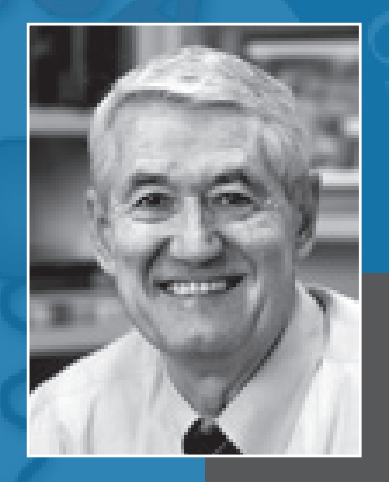

CLIFFORD G. SHULL PRIZE

Robert J. Birgeneau University of California, Berkele

and Lawrence Berkeley National Laboratory

for his seminal scientific contribut
in the field of neutron scaltering

The Clifford G. Shull Prize in Neutron Science recognizes outstanding research in neutron
science and leadership promoting the North American neutron scattering community. The prize is amemed in honor of Clififord G. Shull, who

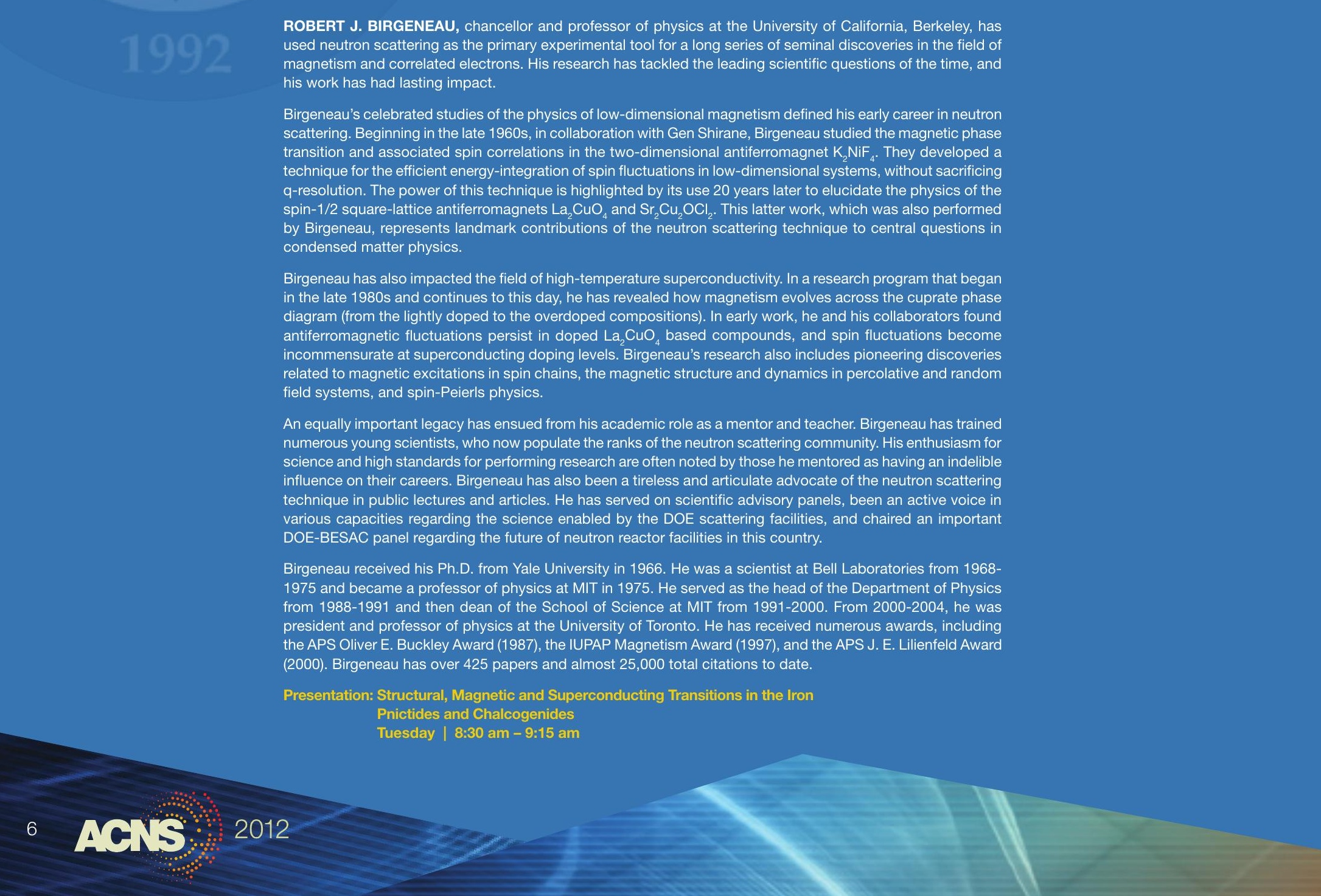

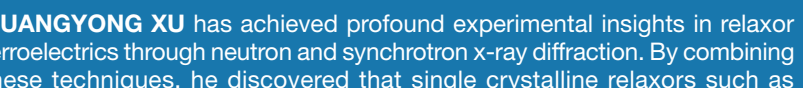

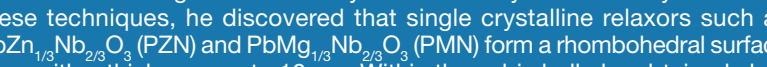

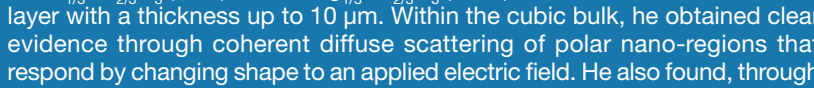

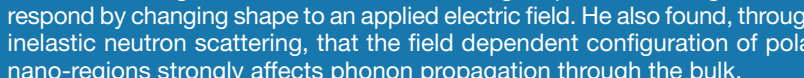
Relaxor ferroelectrics play an increasingly important technological role-PZN
with $4.5 \%$ PbTTi ${ }_{3}$, for example, displaying the largest known piezo-electric

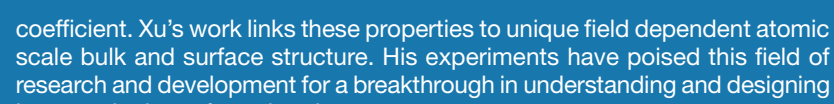
Xu received his Ph.D. in 1999 from Johns Hopkins University and joinec at Brookhaven National Laboration in : Probing Local Polar Structures in PZN-xPT and PMN-XPT
Relaxor Ferroelectrics using Neutron and X-Ray Scattering
Monday | 9:00 am -9:30 am
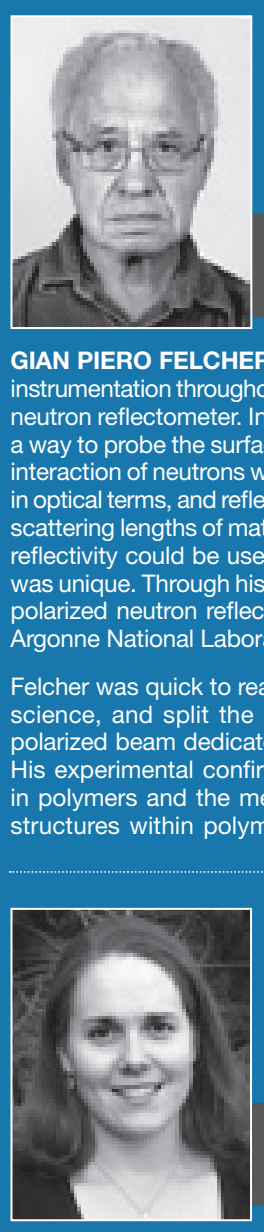

Orainary Portland cement-based (OPC) concrete is the most-used builc
material worldwide and is the second-most-used resourte, after wa

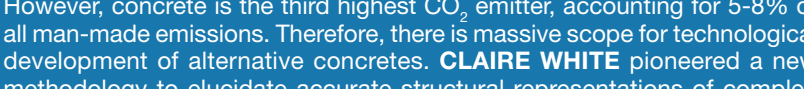
materials by combining neutron diffraction and compunutationolal chemistry.
She used the disordered aluminosilicate material metakaolin, an alternati She used the disordered aluminosilicate material, metakaolin, an alterna
cement precursor, as the case study, with the methodology revealing
xistence of existence of III-coordinated aluminum, which has never before been snoth
to exist in this material. This sesearch exemplified the power of combining
local structural data (i.e., neutron pair distribution function analysis) with first-principles calculations for amorphous materialis, sespecially when used
in an iterative manner to maintain thermodynamic feasibility and agreement

White has also been heavily involved in technique development with respect
to incoherent scattering and neutron pair distribution function analysis.

e Los Alamos National Laboratory
For hydrogen and other inconerent scattering elements, the neutron par

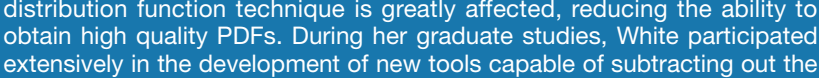
extensively in the aevelopment of new tools capabel of shat
incoherent scattering component of total scattering data.

White graduated from The University of Melloourne in 2010, and is currentty a
Director's Postdoctoral Fellow at Los Alamos National Laboratotor, with a joint opointment tinvolving the Lujan Neutron Scattering Center and the Theoretical
vision. Her research involves combining theoretical and experiment anniques to advance the understanding of low $\mathrm{CO}_{2}$ cements (geopolymers
d associated materials. She is active in the area of technique development and is con
simulation

Presentation: Recent Progress in Elucidating Accurate Structural
Representations of Disordered Complex Materials
Wednesday | 9:00 am - $9: 30 \mathrm{am}$

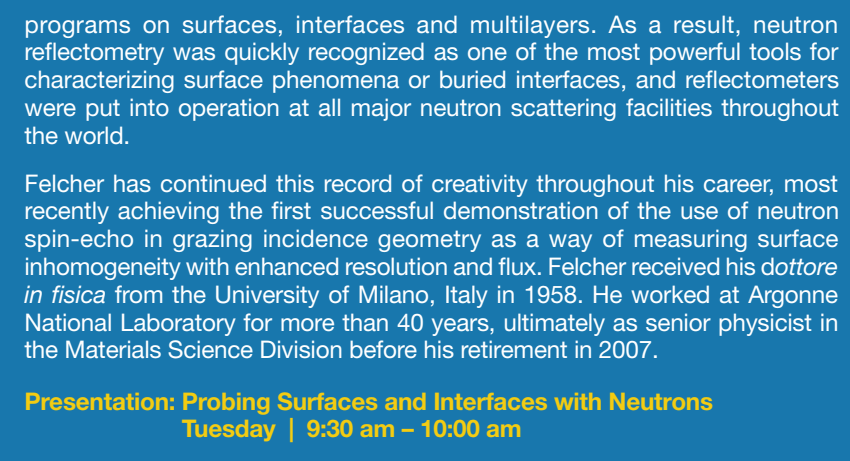

This talk will be presented by Suzanne te Velthuis on behalf of Felcher.

honors outstanding accomplishments in the general area of neutron scattering 


\section{DALIY SCHEDULE OF EVENTS}

SUNDAY, JUNE 24

Registration................
South Gallery Foyer Tutorial: Advances in Time-of-Flight Tutorial: Novel Techniques Welcome Reception Exhibit...............
Room C/FiH

\section{CONFERENCE BANQUET}

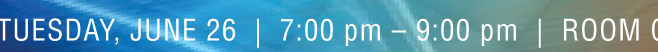
$\$ 75.00$ per person Tickets available at Registration Desk

\section{Robert D. Shull}

A Memoir of Clifford G. Shull, Neutron Scattering at the Beginning

\section{Sam Werner}

The Founding of NAS

\section{MONDAY, JUNE 25}

Registration............................................. 7:30 am - 7:30 pm
South Gallery Foyer A1: Plenary/Prize Lectures. $\ldots \ldots 8: 20$ am $-10: 00$ a

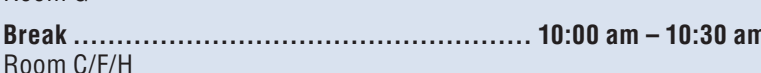
... 10:00 am - 10:30 am Exhibit............
Room C/F/H B1: Instrumentation for Large Structures
and Long Time Scales.............................. 10:30 am - 12:15 pm

D1: High-Tr Spin Dynamics Room $G$

E1: Biomembranes................................. 10:30 am - 12:00 p Room D/E G1: Mechanical Behavior

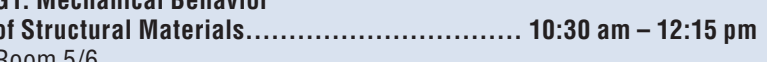
Lunch (Not provided by Conference) ................. 12:15 pm - 1:45 pm Poster Authors Set-up ............... B2: Instrumentation - New Techniques ...............1:45 pm - 3:30 pm Room $G$

C1: Polyelectrolytes and Wat

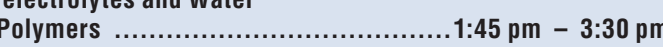

F1: Absorption and Separation,

MOFs and Zeolites ...................................:45 pm - 3:30 p

G2: Energy Conversion Materials......................1:45 pm - 3:30 pm

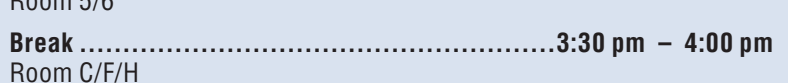
Room C/FI/H

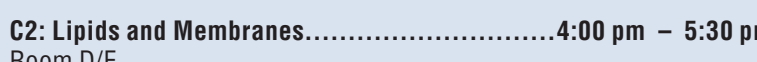
D2: Magnetism of Nanostructured Materials ......4:00 pm - 5:30 pm F2: Local Structure ................................ 4:00 pm - 5:30 pm H1: Neutron Physics I ................................. 4:00 pm - 5:15 pm Room $5 / 6$

Poster Session - General Viewing ......................6:00 pm - 7:30 pm
Room C/FIH

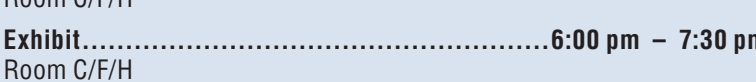

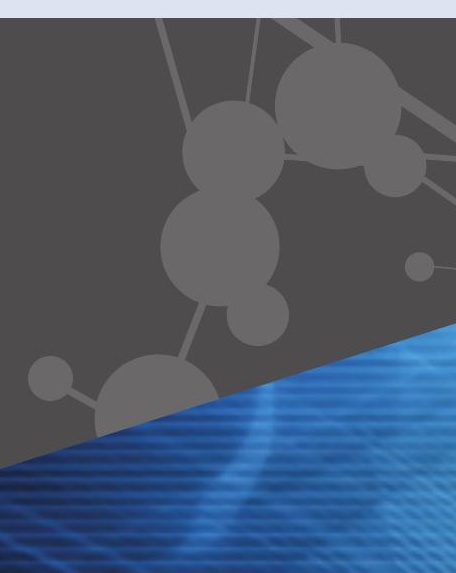

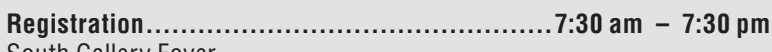
South Gallery Foy

A2: Prize/Plenary Lectures; Award Presentation

Break ..............
Room C/F

Exhibit.................
Room C/F/H

............................. 10:30 am B3: Sources and Detectors....................... 10:30 am - 12:15 pm D3: Superconductivity .............................. 10:30 am - 12:15 pm
Room G

G3: High Temperature
and Radiation Resistant Materials................ 10:30 am - 12:15 pm Room 5/6 Lunch (Not provided by Conference) . Poster Authors Set-up ................................1:00 pm - 3:30 pm D4: Control of Bulk Properties
Through Materials Engineering ......................1:45 pm - 3:00 pm E2: Protein Structure and Assocations ..............1:45 pm - 3:00 pm Room D/E

F3: Neutron Spectroscopic Studies Room A/B H2: Neutron Physics II ................................1:45 pm - 3:00 pm

Break .............
Room C/F

$.3: 00 \mathrm{pm}-3: 30 \mathrm{pm}$

Exhibit..............
Room C/F

$.3: 00 \mathrm{pm}-5: 30 \mathrm{pm}$

Poster Session - General Viewing .....................3:30 pm - 5:30 pm
Room C/F/H
Com

Conference Banquet.................................. 7:00 pm - 9:00 pm
Room G C3: Confined and Porous Systems.................. 10:30 am - 12:15 pm

Registration................
South Gallery Foyer

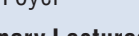

ding Student Poster Announcement....8:30 am - 10:00 am

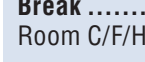
10:00 am - 10:30 am

Exhibit.............. ... 10:00 am - 10:30 am B4: Optics and Polarization ......................... 10:30 am - 12:15 pm C4: Complex Fluids and Gels ..................... 10:30 am - 12:15 pm
Room D/E
D5: Multiferroics and Complex Oxides $\ldots 10.30 \mathrm{am}-12: 15 \mathrm{pm}$ D5: Mul
Room G Lunch (Not provided by Conference) ................ 12:15 pm - 1:45 pm

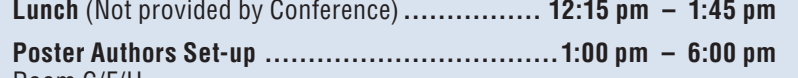

C5: Polymers and Films ...............................1:45 pm - 3:30 pm

D6: Frustrated and Novel Magnetism................1:45 pm - 3:30 pm Room $G$ E3: Stability and Dynamics ......................1:45 pm - 3:30 pm G4: Energy Storage Materials .......................1:45 pm - 3:15 pm

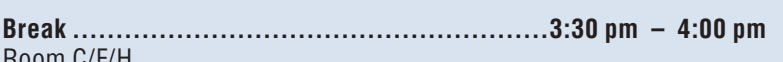
Exhibit........................................3:30 pm - 4:00 pm
Room C/F/H B5: Software for Neutron Data Anyalsis............:400 pm - 5:30 pm C6: Particle-Containing and Clustered Systems ..4:00 pm - 5:30 pm D7: Lattice Dynamics .................................4:00 pm - 5:30 pm

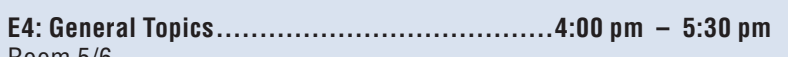
Room $5 / 6$ Poster Session - General Viewing ....................6:00 pm - 7:30 pm
Room C/F/H Exhibit.................................................6:00 pm - 7:30 pm

THURSDAY, JUNE 28

Registration............................................ 7:30 am - 10:00 am

NIST - NCNR Tour ............................... 8:00 am - 1:30 pm

ADVANCED SIGN-UP WAS REQUIRED

- Continental Breakfast a 8:00 am for Tour Participants ONLY - Tour is from 10:00 am - 12:00 pm

- Buses will return to Georgetown University at approx. 1:30 pm Transportation Assistance from NIST to Airport will be available up reques. 


\section{TUTORIALS}

SUNDAY, JUNE 24

Advances in Time-of-Flight Powder Diffraction | Room D

This tutorial will give a practical overview of the current state of the art in time-of-flight neutron powder difraction. Topics include an introduction to powder diffraction and the pair distribution

Chair Ashfia Huq Oak Ridge National Laboratory

1:00 pm-1:45 pm Introduction to TOF Powder Diffraction

Ashfia Huq Oak Ridge National Laboratory

1:45 pm-2:30 pm Introduction to Pair Distribution Function analysis

Emil Bozin Brookhaven National Laboratory

Break

3:00 pm -3:45 pm TOF Event data and stroboscopic diffraction measurements

KeAn Ork idge Nabina Laboratory

3:45 pm-4:30 pm Parametric neutron powder diffraction

$4: 30 \mathrm{pm}$

Speaker to be Determined

Novel Techniques for Small Angle Neutron Scattering | Room E

This tutorial will highlight some of the novel, cutting edge advances in small-angle neutron
scattering (SANS). II will feature four topics: rheological SANS under shear (RHEO-SANS),

time-resolved SANS (TISANE), polarization analyzed SANS (PASANS) for magnetic systems,

and SASSIE, an adaptable computational suite for solving complex structures. These lectures
will include a lively mixture of experimental highlights, theory, supporting software, and practica will include a lively mixture of experimental highlights, and attendees are encouraged to engage
hands-on information. The lecturers are expert users, and them. There will be time set aside for lengthy discussion during the coffee break and the final open discussion period

Chair Kathryn Krycka NIST Center for Neutron Research

1:00 pm-1:05 pm Brief Introduction

1:05 pm-1:50 pm Rheo-SAN

Rheo-SANS: Rheology and Shear C

1:50 pm - 2:35 pm TISANE: Time-Resolved Small Angle Neutron Scattering

and Gähler Institut Laue-Langevin

3:00 pm-3:45 pm Polarization Analysis: Resolving Structural and Magnetic Scattering

3.45 pm-4.30 pm SASsE: Conp

Hailiang Zhang NIST Center for Neutron Research
Nick Clark NIST Center for Neutron Research

$4: 30 \mathrm{pm}$

AGNS: 2012 


\section{ORAL PRESENTATIONS AT-A-GLANCE}

TUESDAY, JUNE 26

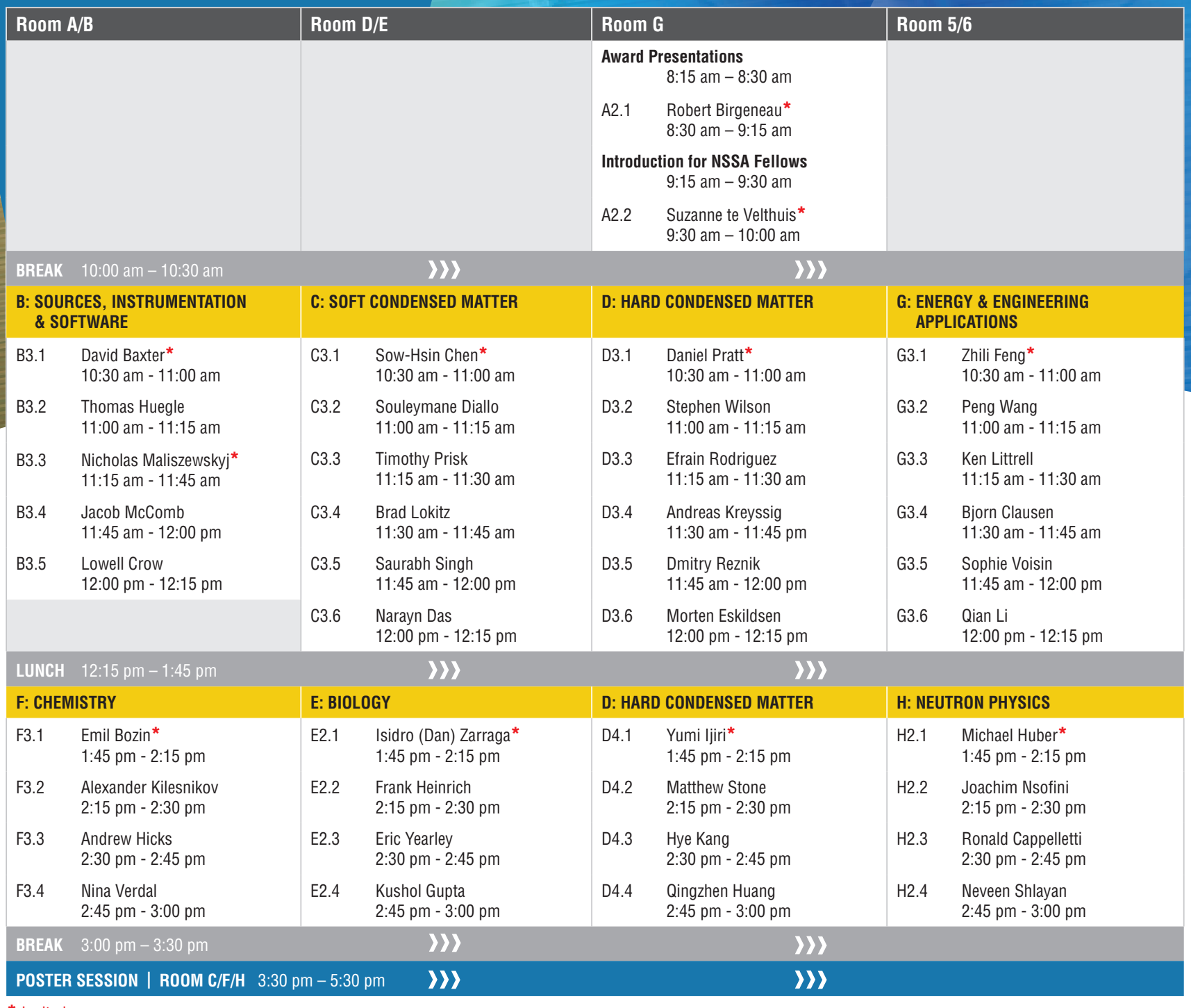

\section{Mark Your Calendar For ICNS}

ACNS 2012
WEDNESDAY, JUNE 27

Room $A / B$ Room D/E

Introductions

A3.1 $\begin{aligned} & \text { Yasuhiko Fujiii } \\ & 8: 35 \text { am }-8: 50 \text { am }\end{aligned}$ Outstanding Student Poster

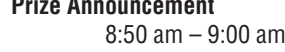

$\begin{array}{ll}\text { A3.2 } & \text { Claire White } \\ & 9: 00 \text { am }-9: 30 \text { am }\end{array}$

A3.3 Leon Balents
9:30 am $-10: 00 \mathrm{am}$

\begin{tabular}{l|l|l|l}
$\begin{array}{l}\text { BREAK } \\
\text { B: SOURCES, INSTRUMENTATION }\end{array}$ & C: SOFt CONDENSED MATTER & D: HARD CONDENSED MATTER & F: CHEMIISTRY \\
\& SOFTWARE
\end{tabular}

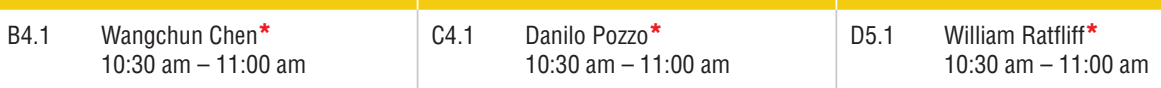

B4.2 Xin Tong

10:30 am $-11: 00$ am
D5.2 Jaehong Jeong

F4.1 Mario Bieringer*
$10: 30 \mathrm{am}-11: 00 \mathrm{am}$

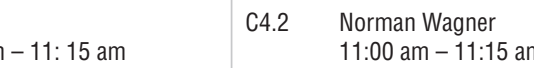

B4.3 Qiang Ye
$11: 15 \mathrm{am}-11: 30 \mathrm{am}$

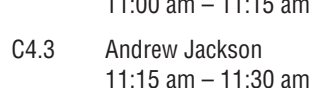

4.4 William Hamilton
$11: 30 \mathrm{am}-11: 45 \mathrm{am}$

D5.3 Jae-Ho Chung 11 am

F4.2 Jing-Tai Zhao
$11: 00$ am $-11: 15$ am

B4.5 Todd Sherline
11:45 am $-12: 00 \mathrm{pm}$

C4.4 Hyuntaek Oh
$11: 30 \mathrm{am}-11: 45 \mathrm{am}$

D5.4 Eduardo Granado
$11: 30 \mathrm{am}-11: 45 \mathrm{am}$

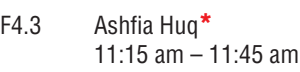

B4.6 Jack Robertson

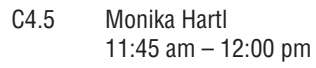

12:00 pm-12:15 pm

C4.6 Hideki Seto

D5.5 Stuart Calder
11:45 am $-12: 00 \mathrm{pm}$

F4.4 Jason Simmons
11:45 am - 12:00 pm

LUNCH $12: 15$ pm-1:45 pr.

D5.6 Joel Helto

$\begin{array}{ll}\text { F4.5 } & \begin{array}{l}\text { Peng Wang } \\ \text { 12:00 } \mathrm{pm}-12: 15 \mathrm{pm}\end{array}\end{array}$

G: ENERGY \& ENGINEERIN
APPLICATIONS

\begin{tabular}{ll} 
G4.1 & John Tse \\
& 1:45 pm-2:15 pm \\
\hline Ge.2 & a
\end{tabular}

$\begin{array}{ll}\text { G4.2 } & \begin{array}{l}\text { Abhiiji Pramanick } \\ 2: 15\end{array} \\ \text { pm - 2:30 pm }\end{array}$

64.3 Michael Lerche
2:30 $\mathrm{pm}-2: 45 \mathrm{pm}$

$\begin{array}{ll}\text { G4.4 } & \text { Howard Wang } \\ & 2: 45 \mathrm{pm}-3: 00 \mathrm{pm}\end{array}$

G4.5 Joseph Dura
3:00 pm - 3:15 pm

C: SOFT CONDENSED MATTER

\》

D: HARD CONDENSED MATTER

E: BIOLOGY

$\begin{array}{ll}\text { C5.1 } & \text { Xiaohua Zhang } \\ & \text { 1:45 pm-2:00 pm }\end{array}$

$\begin{array}{ll}\text { D6.1 } & \text { Seung-Hun Lee } \\ & \text { 1:45 pm- 2:15 pm } \\ & \text { Do }\end{array}$

C5.2 Ralf Koehler
2:00 $\mathrm{pm}-2.15$

$\begin{array}{ll}\text { D6.2 } & \text { Yang Zhao } \\ 2: 15 \mathrm{pm}-2: 30 \mathrm{pm}\end{array}$

\begin{tabular}{ll} 
C5.3 Manish Kulkarni \\
& $2: 15 \mathrm{pm}-2: 30 \mathrm{pm}$ \\
\hline &
\end{tabular}

C5.4 Chris Garvey
$2: 30 \mathrm{pm}-2: 45 \mathrm{pm}$

C5.5 Madhu Sudan Tyagi

$\begin{array}{ll}\text { C5.6 } & \text { Hyungijin Lee } \\ & 3: 00 \mathrm{pm}-3: 15 \mathrm{pm}\end{array}$

D6.3 Katharina Fritsch
2:30 pm - 2:45 pm

D6.4 Travis Williams
2:45 pm - 3:00 pm

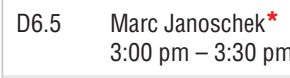

E3.1 Christopher Roberts ${ }^{*}$

E3.2 Liang Hong
2:15 pm - 2:30 pm

E3.3 Haskell Taub
$2: 30 \mathrm{pm}-2: 45 \mathrm{pm}$

$\begin{array}{ll}\text { E3.4 Sung-Min Choi } & \text { 2:05 } \\ \text { 2:45 } 3: 00 \text { pm }\end{array}$

E. Melissa Sharp
3:00 pm $-3: 15 \mathrm{pm}$

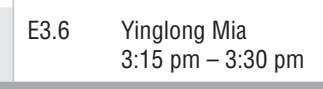

BREAK $3: 30 \mathrm{pm}-4: 00 \mathrm{pm}$ IX)

B: SOURCES, INSTRUMENTATIO
\& SOFTWARE

C: SOFT CONDENSED MATTER

$\begin{array}{ll}\text { B5.1 } & \text { Brian Maranville } \\ & \text { 4:00 pm - 4:15 pm }\end{array}$

B5.2 Konstantin Berlin
4:15 pm - $4: 30 \mathrm{pm}$

$\begin{array}{ll}\text { B5.3 Mathieu Doucct } & { }^{*} \\ & 4: 30 \mathrm{pm}-5: 00 \mathrm{pm}\end{array}$

$\begin{array}{ll}\text { B5.4 } & \text { Raymond Osborn } \\ & 5: 00 \mathrm{pm}-5: 15 \mathrm{pm}\end{array}$

B5.5 Andrei Savici
5:15 pm- $-5: 30 \mathrm{pm}$

C6.1 Vivek Prabhu*
4:00 pm-
p::30 pm

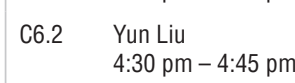

C6.3 Adam Washington

$4: 45 \mathrm{pm}-5: 00 \mathrm{pm}$

$\begin{array}{ll}\text { C6.4 } & \text { Mathew Barrett } \\ & 5: 00 \mathrm{pm}-5: 15 \mathrm{pm}\end{array}$

C6.5 Saurabh Singh
$5: 15 \mathrm{pm}-5: 30 \mathrm{pm}$

\begin{tabular}{|ll} 
D7.1 & Douglas Abernathy \\
& $4: 00 \mathrm{pm}-4: 15 \mathrm{pm}$ \\
&
\end{tabular}

E: BIOLOGY

\begin{tabular}{|ll} 
E4.1 & Susan Krueger \\
$4: 00 \mathrm{pm}-4: 15$
\end{tabular}

$\begin{array}{ll}\text { D7.2 } & \text { Olivier Delaire } \\ & 4: 15 \mathrm{pm}-4: 30 \mathrm{pm}\end{array}$

D7.3 Chen Li
4:30 pm- 4:45 pm

$\begin{array}{ll}\text { D7.4 Adam Aczel } \\ & \text { 4:45 pm }-5: 00 \mathrm{pm} \\ & \text { D7.5 }\end{array}$

D7.5 Louis Santodonato
5:00 pm -5:15 pm

$\begin{array}{ll}\text { D7.6 } & \text { Henry Glyde } \\ & 5: 15 \mathrm{pm}-5: 30 \mathrm{pm}\end{array}$

E4.2 Tatiana Perevozchikova

$\begin{array}{ll}\text { E4.3 } & \begin{array}{c}\text { Sylvia Junnhans } \\ 4: 30 \mathrm{pm}-4: 45 \mathrm{pm}\end{array}\end{array}$

E4.4 Silddharth Shenoy
4:45 pm - 5:00 pm

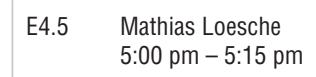

E4.6 Xiang-ciang Chu 


\section{POSTER PRESENTATIONS AT-A-GLANCE}

Poster Authors Set-up $\begin{array}{ll}\text { Monday } & \text { 1:00 pm - 6:00 pm } \\ \text { Tuesday } & 1: 00 \mathrm{pm}-3: 30 \mathrm{pm} \\ \text { Wednesday } & 1: 00 \mathrm{pm}-6: 00 \mathrm{pm}\end{array}$

MONDAY, JUNE 25

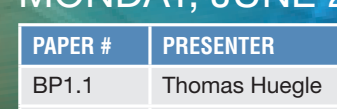

\begin{tabular}{ll}
\hline Melissa Sharp \\
\hline PP1.2
\end{tabular}

BP1.3 Michael Fleenor

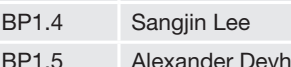

\begin{tabular}{lll} 
BP1.6 John Barker & \\
\hline BP1.7 Carrie Y. Gao
\end{tabular}

CP1.1 Jung Min Kim

CP1.2 Kathleen Weigandt

CP1.3 Nestor Valadez-Perez

\begin{tabular}{l|l|}
\hline CP1.4 & Paul Godrin \\
\hline CP1.5 & Rana Asnkar \\
\hline
\end{tabular}

\begin{tabular}{l|l} 
CP1.5 & Rana Ashkar \\
\hline CP1.6 & Sameer Sathaye \\
\hline
\end{tabular}

CP1.7 Marilia do Rego barros

CP1.8 Andrea Woodka

DP1.1 Brian Kirby

DP1.3 Gary Mankey

DPP.4. Igor Zallz
DP1.5 Jian Yu

\begin{tabular}{lll}
\hline DPP. & Jan Yau \\
\hline DP1.6 Lampen &
\end{tabular}

\begin{tabular}{lll}
\hline DP1.6 & Paula Lampen \\
\hline DP1.7 & Kathrnn Krycka
\end{tabular}

DP1.8 Liza Hashim

DP1.9 Steven Spurge

\begin{tabular}{lll}
\hline DP1.9 & Steven Sp \\
\hline DP1.10 & Binod Rai \\
\hline DP1.
\end{tabular}

\begin{tabular}{l|l} 
DP1.11 Daniel Pajerowsk \\
\hline DP1.12
\end{tabular}

\begin{tabular}{|l|l|}
\hline DP1.12 & Huibo Cao \\
\hline DP1.13 & Jooseop Lee \\
\hline
\end{tabular}

DP1.14 Zhijun Xu

EP1.1 Chris Garvey

EP1.2 William Heller

EP1.3 Ella Mihailescu

EP1.4 Laura Toppozini

EP1.5 John Katsaras

EP1.6 Jianjun Pan

\begin{tabular}{|l|l|}
\hline EP1.7 & David Worcester \\
\hline FP1.1 & Brian Frederick \\
\hline
\end{tabular}

\begin{tabular}{lll} 
FP1.1 & Brian Frederick \\
\hline FP1.2 & Minzhong Xu \\
\hline
\end{tabular}

FP1.3 Monika Hartl

FP1.4 Ebru Kizilay

GP1.1 Liwwi Huang

GP1.3 Lalitha Ganapatibho

GP1.4 Jim Browning

GP1.5 Jose Banuelos

\begin{tabular}{|c|c|}
\hline PAPER \# & \begin{tabular}{|l|l|} 
PRESENTER \\
\end{tabular} \\
\hline BP2.1 & Haitham Abdel Maijd \\
\hline BP2.2 & Sangiin Lee \\
\hline BP2.3 & Lisa DeBeer-Schmitt \\
\hline BP2.4 & Peng Wang \\
\hline BP2.5 & Richard Weber \\
\hline BP2.6 & Rebecca Mills \\
\hline BP2.7 & Wangchun Chen \\
\hline BP2.8 & Daniel Brown \\
\hline BP2.9 & Chenyang Jiang \\
\hline BP2.10 & Melissa Sharp \\
\hline CP2.1 & Wei-Shan Chiang \\
\hline CP2.2 & Christopher Bertrand \\
\hline CP2.3 & Dongcui Li \\
\hline CP2.4 & Gregory Newbloom \\
\hline CP2.5 & Jeffrey Richards \\
\hline CP2.6 & Jiahua Zhu \\
\hline CP2.7 & Jungiy Ryu \\
\hline DP2.1 & Yaohua Liu \\
\hline DP2.2 & Gary Mankey \\
\hline DP2.3 & Brian Maranville \\
\hline DP2.4 & Gregory Tucker \\
\hline DP2.5 & Sachith Dissanayake \\
\hline DP2.6 & Kemp Plumb \\
\hline DP2.7 & Stephen Daunheimer \\
\hline DP2.8 & Ryan Morrow \\
\hline DP2.9 & Binod Rai \\
\hline DP2.10 & G. Granroth \\
\hline DP2.11 & Jerod Wagman \\
\hline DP2.12 & Robert McQueeney \\
\hline DP2.13 & Jagat Lamsal \\
\hline DP2.14 & Timothy Prisk \\
\hline EP2.1 & Zvi Kelman \\
\hline EP2.2 & Amit Vaish \\
\hline EP2.3 & Joon Ho Roh \\
\hline EP2.4 & Derya Vural \\
\hline EP2.5 & Ann S. Junghans \\
\hline EP2.6 & Sylvia Junghans \\
\hline FP2.1 & Nathan Hould \\
\hline FP2.2 & Nathaniel Bass \\
\hline FP2.3 & Harshita Kumari \\
\hline GP2.1 & Wei Chen \\
\hline GP2.2 & Brett Guralnick \\
\hline GP2.3 & Hao Shen \\
\hline GP2.4 & Wenluan Zhang \\
\hline GP2.5 & David Jacobson \\
\hline & \\
\hline & David Worcester \\
\hline
\end{tabular}

HP1.2 Devander Deyhis
General Viewing | Room CHF $\begin{array}{ll}\text { Monday } & 6: 00 \mathrm{pm}-7: 30 \mathrm{pm} \\ \text { Tuesday } & 3: 30 \mathrm{pm}-5: 30 \mathrm{pm} \\ \text { Wednesday } & 6: 00 \mathrm{pm}-7: 30 \mathrm{pm}\end{array}$

WEDNESDAY, JUNE 27 \begin{tabular}{|l|l|l|}
\hline PAPER \# & PRESENTER \\
\hline BP3.1 & X. Yang \\
\hline
\end{tabular}

\begin{tabular}{l|l}
\hline BP3.1 & X. Yang \\
\hline BP3.2 & Harley Skorpenske \\
\hline BP33. & Alex
\end{tabular}

BP3.3 Alexander Deyhim

\begin{tabular}{|l|l}
\hline BP3.4 & Jinkui Zhao \\
\hline BP3.5. & Chun-Ming Wu \\
\hline
\end{tabular}

BP3.5 Chun-Ming Wu

\begin{tabular}{ll}
\hline BP3.6 & Wangchun Chen \\
\hline BP3.7 & Alexandre lvanov \\
\hline P &
\end{tabular}

BP3.8 Richard Azuah

BP3.9 Ken Littrell

CP3.1 Peter Holden

\begin{tabular}{|l|l|}
\hline CP3.2 & Aldona Rajewska \\
\hline CP3.3 & Andrew Miskowiec \\
\hline CP34 & Ande Wooda \\
\hline
\end{tabular}

$\begin{array}{ll}\text { CP3.3 } & \text { Andrew Miskowiec } \\ \text { CP3.4 Andrea Woocka }\end{array}$

CP3.5 Zheng Yi

CP3.6 Saurabh Singh

\begin{tabular}{ll} 
CP3.7 & Bulent Akgun \\
\hline CP3.8 & Antonio Faraone \\
\hline
\end{tabular}

CP3.9 Michihiro Nagao

CP3.10 Jong Keum
DP3.1 Chenyang Shi

$\begin{array}{ll}\text { DP3.1 } & \text { Chenyang Shi } \\ \text { DP3.2 Hillary Smith }\end{array}$

DP3.3 loanna Bakaimi

DP3.4 Gregory MacDougall

\begin{tabular}{ll} 
DP3.5 & Despina Louca \\
\hline DP3.6 Andrey Podlesnyak &
\end{tabular}

\begin{tabular}{ll} 
DP. & Andrey Podles \\
DP.7 & Chris Stock \\
\hline
\end{tabular}

DP3.8 Valery Kiryukhi

DP3.9 Kazuki lida

\begin{tabular}{|l|l|}
\hline DP3.10 & Eugene Iolin \\
\hline DP3.11 & Victor Fanelli \\
\hline
\end{tabular}

\begin{tabular}{ll}
\hline DP3.11 Victor Fanelli \\
\hline DP3.12 Michael Loewenhaup
\end{tabular}

DP3.13 Deepak Singh

\begin{tabular}{|l|l|}
\hline DP3.14 & Peng Wang \\
\hline DP3.15 & Henry Glyde \\
\hline
\end{tabular}

\begin{tabular}{|l|l|}
\hline DP3.15 & Henry Glyde \\
\hline EP3.1 & Vitalii Silin \\
\hline
\end{tabular}

EP3.2 Shih-Chun Huang

EP3.3 William O'Dell

EP3.4 Sylvia Junghans

\begin{tabular}{l|l}
\hline GP3.1 & Dong Ma \\
\hline GP3.2 & Peter Liaw \\
\hline
\end{tabular}

GP3.3 Lilin $\mathrm{He}$

GP3.4 Xun-Li Wang

A: Plenary \& Prize Sessions

B: Sources, Instrumentation \& Software

C: Soft Condensed Matter

D: Hard Condensed Matter

$\begin{array}{ll}\text { E: } & \text { Biology } \\ \text { F: Chemistry }\end{array}$

F: Chemistry

G: Energy \& Engineering Applications

H: Neutron Physics

\section{SPECIAL THANKS}

This conference has been funded, in part, by the generous contributions from these organizations:

LUJAN CENTER

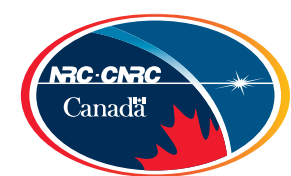

(ㄱ)

NLT

○ORNL NEUTRON SCIENCES

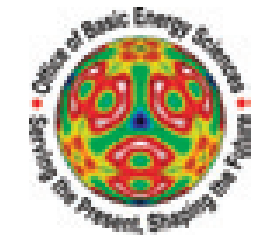

Lujan Neutron Scattering Center Los Alamos Neutron Science Center lansce.lanl.gov/lujan

National Research Council Canada Canadian Neutron Beam Centre www.nrc-cnrc.gc.ca/cnbc

The Neutron Scattering Society of America www.neutronscattering.org

NIST Center for Neutron Research www.ncnr.nist.gov

Oak Ridge National Laboratory Neutron Sciences Directorate neutrons.ornl.gov

U.S. Department of Energy Office of Basic Energy Sciences science.energy.gov/bes

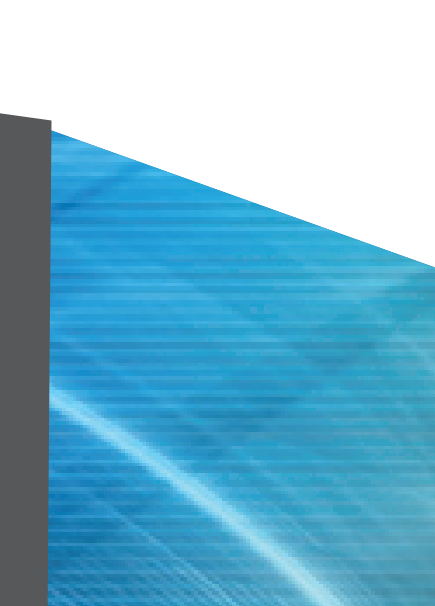




\section{ACNS EXHIBITOR PROFILES}

\section{WELCOME TO THE ACNS 2012 EXHIBIT}

Georgetown University Hotel and Conference Center Room C/F/H

\section{EXHIBIT HOURS}

$\begin{array}{lrl}\text { Sunday } & 5: 00 \mathrm{pm} & -8: 00 \mathrm{pm} \\ \text { Monday } & 10: 00 \mathrm{am} & -10: 30 \mathrm{am} \\ & 3: 30 \mathrm{pm} & -4: 00 \mathrm{pm} \\ & 6: 00 \mathrm{pm} & -7: 30 \mathrm{pm} \\ \text { Tuesday } & 10: 00 \mathrm{am} & -10: 30 \mathrm{am} \\ & 3: 00 \mathrm{pm} & -5: 30 \mathrm{pm} \\ \text { Wednesday } & 10: 00 \mathrm{am} & -10: 30 \mathrm{am} \\ & 3: 30 \mathrm{pm} & -4: 00 \mathrm{pm} \\ & 6: 00 \mathrm{pm} & -7: 30 \mathrm{pm}\end{array}$

The ACNS 2012 Exhibit, held in conjunction with the
conferene, will feature displays strom all sectors of the
neutron science community. Convenient to the technical neutron science community. Convenient to the technical
sessions and posters, attendides are encouraged to visit he
exhibit displays to learn more about the latest products the exhibit displays to learn more about the latest prodo vists and
services related to the neutron scattering field.

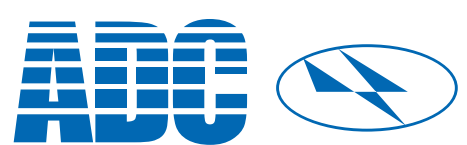

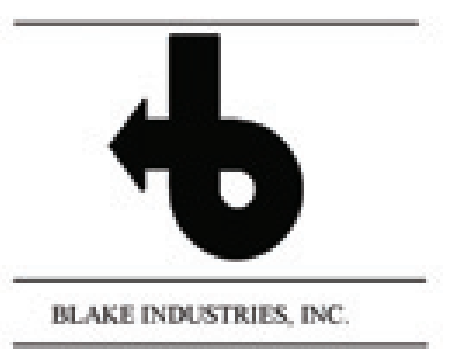

CRYOGRIC
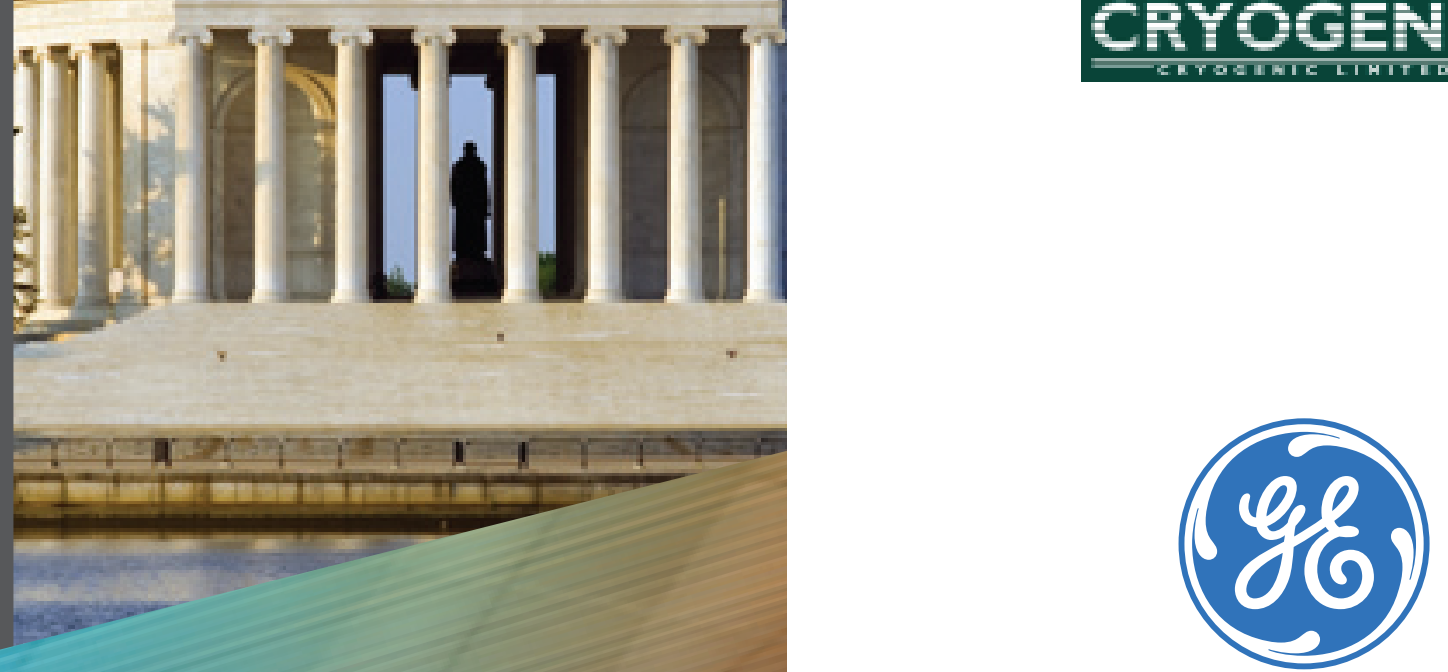

ADC USA, InC.

www.adc9001.com

Key Products: Crossed Roller Jacks \& Slides; Goniometer Stages; Rotation States; Utility

Advanced Design Consulting USA, Inc. is an engineering and scientific consulting firm and a broad array of high-precision components and instruments to commercial, neutron, academic, and government agencies worldwide. ADC's innovative solutions leverage its experlice customers' manufacturing, engineering, and research applications.

BLAKE INDUSTRIES, INC.

blake4xray@att.ne

Key Products: Rotary Tables; Goniometer Heads; Slits Blake Industries is a leader in supplying high precision $x$-ray and neutron instrumentation
to research labs, universities and synchrotron beam lines worldwide. We are the exclusive distributors for Huber instruments in the U.S., Mexico and Canada with multiple installations
at all the North American Synchrotrons and have been supplying x-ray users for over 40 years.

\section{CRYOGENIC LIMITED}

\section{www.cryogenicusa.com}

Key Products: Superconducting Magnets; Measurement Systems; Cryogen Free Systems

Cryogenic Limited has supplied hundreds of Cryogen Free Magnets to the scientific Magnetometry Systems are ayails chith fields un to 20 Testa Contigurations includ solenoids, split pair (to 14T), vector and beam-line magnets. The Cryogen Free Systems have an integrated variable temperature insert which operales to $1.6 \mathrm{~K}$ to $1000 \mathrm{~K}$. Interchangeable Heat Resistivity and Hall Effect probe Rotation Probe Cryogen Free Helium-3 $(280 \mathrm{mK}$ ) or Dilution Refrigerator (10mK) Module. Contact us to make your next experiment Cryogen Free.

GE ENERGY

sensing@ge.com

Key Products: Neutron Scattering Detectors, including Helium-3 Position Sensitive

GE Energy offers the Reuter Stokes product line of detection and measurement systems for reclamation to highly accurate helium 3 position sensitive neutron detectors integrated with reclamation, to highly accurate helium 3 position sensitives
high-speed measurement and data collection electronics. 
JANIS RESEARCH COMPANY, HLC

sales@janis.com
www.janis.com

$\overline{\mathrm{JAN} I S}$

Key Products: 4K \& 10K Cryocooler Systems; Helium-3 Systems; Helium-cooled Variable

Janis Research is a supplier of both closed cycle and LHe cooled systems to the neutron $800 \mathrm{~K}$. We offer "mix and match" tail configurations to allow the same base unit to be used

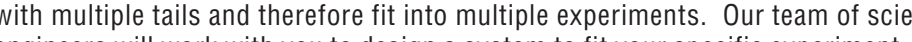

Kurt J.Lesker

MIPO ORONR

Ouality - Retiability - innovation

LUJAN CENTER

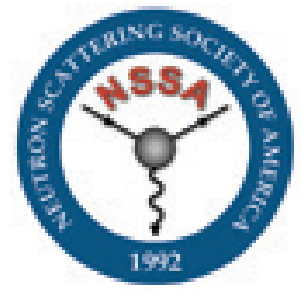

ACNS
KURT J. LESKER COMPANY/MIRROTRON LTD.

sales@lesker.com
www.lesker.com

Key Products: Neutron Guides \& Guide Systems; Mag Lev Bearing Choppers; Beam Slits;

We are global distributors of our partner Mirrotron Ltd.'s quality tools for neutron scattering experiments. Products and services include: neutron guides with super-mirror coating to $m=5.5$ (100\% neutron reflectometer inspected) including converging/focusing and
in-pile designs; mag lev bearing/servo choppers with band-width limiting, Fermi designs in-pile designs; mag lev bearing/servo choppers with band-width limiting, rermi designs
in customized sizes/geometries; complete guide systems, support structures, shielding
and vacuum housings; complemented by an expert worldwide installation/alignment team.

LUJAN NEUTRON SCATTERING CENTER Los Alamos Neutron Science Center (LANSCE) Los Alamos National Laboratory

Key Products: Neutron Scattering

The Lujan Center is a national user facility that offers access to eleven neutron scattering
instruments and three nuclear physics instruments. Neutrons are produced by spallation instruments and three nuclear physics instruments. Neutrons are produced by spallation
using an $800 \mathrm{MeV}$ proton beam at the LANSCE facility. Extreme environment capabilities include temperature, pressure, magnetic field, corrosion and stress. Focus areas include diffraction, total scattering, reflectometry, magnetism, polarized and small-angle scattering.
$20 \mathrm{~Hz}$ operation and liquid hydrogen moderators make the facility well suited for lon $20 \mathrm{~Hz}$ operation and liquid hydrogen moderators make the facility well suited for long
wavelength applications. LANSCE hosts three other user facilities focused on nuclear wavelength applications. LANSCE hosts three other user facilities focused on nuclear
physics, proton radiography and isotope production. Classified and proprietary research can be accommodated upon request. Funding for Lujan is provided by the DOE Office of Basic Energy Sciences.

NEUTRON SCATTERING SOCIETY OF AMERICA

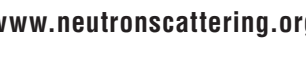

Key Products: American Conference of Neutron Scattering; Clifford G. Shull Prize in
Neutron Science; Sustained Research and Science Prizes; Prize for Outstanding Student Neutron Science; Sustained Ressac
Research; Student Travel Awards

The Neutron Scattering Society of America (NSSA) was established in 1992 to provide class research in neutron scattering. The main goal of the Society is to stimulate, promoand broaden the use of neutron scattering in science, engineering and technology. The NSSA

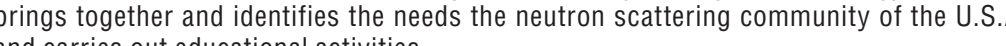

\section{NLT}

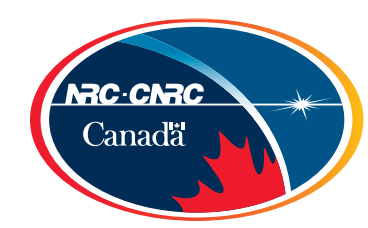

OORIN NEUTRON SCIENCES

\section{䭪 Springer}

the language of science

\section{NIST CENTER FOR NEUTRON RESEARCH}

The NCNR operates 25 instrument stations providing thermal and cold neutrons to the peer-reviewed in 2009 and 350 papers were published based on completed experiments. Research ranges from physical and life sciences to fundamental neutron physics, earth science and engineering. Cold neutron instruments are especially featured at the facility instrument stations.

\section{URC CANADIAN NEUTRON BEAM CENTR}

\section{wwww.nrc-cnrc.gc.ca/cnbc}

Key Products: Research Facility; Fundamental and Applied Research

The National Research Council-Canadian Neutron Beam Centre (NRC-CNBC) enables 200 scientists, engineers, and students from universities, government labs and industry

OAK RIDGE NATIONAL LABORATORY, NEUTRON SCIENCES DIRECTORATE

\section{neutronusers@ornl.gov}

neutrons.ornl.gov

Key Products: Research Facility: Fundamental Research

Oak Ridge National Laboratory, managed by UT-Battelle, LLC, for the U.S. Department of Energlation Neutron Source is an accelerator-based pulsed spallation neutron source and is the most powerful pulsed spallation neutron source in the world. The High Flux Isotope

SPRINGER

www.springer.com

Key Products: Books; Journals; eBooks

With more than 2,100 books currently available in the Chemistry and Materials Science eBook publication model is called SpringerBriefs SpringerBriefs are short books Springers lates allow authors to retain copyright, they are published in 8-12 weeks, and authors get paid a flat fee on publication. . Come to our both and discuss your Springerbriefs project with the 
Invited Speaker Index

\begin{tabular}{|c|c|c|c|c|c|}
\hline Name & Paper \# & Session Title & Date & Time & Room \\
\hline Agnew, Sean & *G1.1 & G1: Mechanical Behavior of Structural Materials & Monday, June 25 & $10: 30 \mathrm{am}$ & Room 5/6 \\
\hline $\mathrm{An}, \mathrm{Ke}$ & *B2.3 & B2: Instrumentation - New Techniques & Monday, June 25 & $2: 30 \mathrm{pm}$ & Room G \\
\hline Ashkar, Rana & *B1.1 & B1: Instrumentation for Large Structures and Long Time Scales & Monday, June 25 & $10: 30 \mathrm{am}$ & Room A/B \\
\hline Baxter, David & *B3.1 & B3: Sources and Detectors & Tuesday, June 26 & $10: 30 \mathrm{am}$ & Room A/B \\
\hline Bieringer, Mario & ${ }^{\star} \mathrm{F} 4.1$ & F4: Structural Studies & Wednesday, June 27 & $10: 30 \mathrm{am}$ & Room 5/6 \\
\hline Bird, Mark & *B2.1 & B2: Instrumentation - New Techniques & Monday, June 25 & $1: 45 \mathrm{pm}$ & Room G \\
\hline Bozin, Emil & ${ }^{\star} \mathrm{F} 3.1$ & F3: Neutron Spectroscopic Studies of New Materials & Tuesday, June 26 & $1: 45 \mathrm{pm}$ & Room A/B \\
\hline Chen, Sow-Hsin & ${ }^{\star} \mathrm{C} 3.1$ & C3: Confined and Porous Systems & Tuesday, June 26 & $10: 30 \mathrm{am}$ & Room D/E \\
\hline Chen, Wangchun & *B4.1 & B4: Optics and Polarization & Wednesday, June 27 & $10: 30 \mathrm{am}$ & Room A/B \\
\hline Dai, Pengcheng & *D1.1 & D1: High-Tc Spin Dynamics and Superconducting Resonance & Monday, June 25 & $10: 30 \mathrm{am}$ & Room G \\
\hline Doucet, Mathieu & *B5.3 & B5: Software for Neutron Data Anyalsis & Wednesday, June 27 & $4: 30 \mathrm{pm}$ & Room A/B \\
\hline Feng, Zhili & *G3.1 & G3: High Temperature and Radiation Resistant Materials & Tuesday, June 26 & $10: 30 \mathrm{am}$ & Room 5/6 \\
\hline Fultz, Brent & *G2.5 & G2: Energy Conversion Materials & Monday, June 25 & 3:00 pm & Room 5/6 \\
\hline Harroun, Thad & ${ }^{\star} \mathrm{E} 1.1$ & E1: Biomembranes & Monday, June 25 & $10: 30 \mathrm{am}$ & Room D/E \\
\hline Huber, Michael & *H2.1 & H2: Neutron Physics II & Tuesday, June 26 & $1: 45 \mathrm{pm}$ & Room 5/6 \\
\hline Huq, Ashfia & ${ }^{\star} \mathrm{F} 4.3$ & F4: Structural Studies & Wednesday, June 27 & $11: 15 \mathrm{am}$ & Room 5/6 \\
\hline ljiri, Yumi & *D4.1 & D4: Control of Bulk Properties Through Materials Engineering & Tuesday, June 26 & $1: 45 \mathrm{pm}$ & Room G \\
\hline Janoschek, Marc & *D6.5 & D6: Frustrated and Novel Magnetism & Wednesday, June 27 & 3:00 pm & Room G \\
\hline Krishnamoorti, Ramanan & ${ }^{*} \mathrm{C} 2.1$ & C2: Lipids and Membranes & Monday, June 25 & 4:00 pm & Room D/E \\
\hline Lee, Seung-Hun & *D6.1 & D6: Frustrated and Novel Magnetism & Wednesday, June 27 & $1: 45 \mathrm{pm}$ & Room G \\
\hline Leighton, Chris & *D2.1 & D2: Magnetism of Nanostructured Materials & Monday, June 25 & 4:00 pm & Room G \\
\hline Liu, Chen-Yu & ${ }^{*} \mathrm{H} 1.1$ & H1: Neutron Physics I & Monday, June 25 & 4:00 pm & Room 5/6 \\
\hline Liu, Kai & *D2.4 & D2: Magnetism of Nanostructured Materials & Monday, June 25 & $5: 00 \mathrm{pm}$ & Room G \\
\hline Lobo, Raul & ${ }^{*} \mathrm{~F} 1.1$ & F1: Absorption and Separation, MOFs and Zeolites & Monday, June 25 & $1: 45 \mathrm{pm}$ & Room A/B \\
\hline Maliszewskyj, Nicholas & *B3.3 & B3: Sources and Detectors & Tuesday, June 26 & $11: 15 \mathrm{am}$ & Room A/B \\
\hline Maranas, Janna & ${ }^{\star} \mathrm{C} 1.1$ & C1: Polyelectrolytes and Water Soluble Polymers & Monday, June 25 & $1: 45 \mathrm{pm}$ & Room D/E \\
\hline Norman, Michael & *D1.5 & D1: High-Tc Spin Dynamics and Superconducting Resonance & Monday, June 25 & $11: 45 \mathrm{am}$ & Room G \\
\hline Picker, Ruediger & *H1.2 & H1: Neutron Physics I & Monday, June 25 & $4: 30 \mathrm{pm}$ & Room 5/6 \\
\hline Pozzo, Danilo & ${ }^{\star} \mathrm{C} 4.1$ & C4: Complex Fluids and Gels & Wednesday, June 27 & $10: 30 \mathrm{am}$ & Room D/E \\
\hline Prabhu, Vivek & ${ }^{\star} \mathrm{C} 6.1$ & C6: Particle-Containing and Clustered Systems & Wednesday, June 27 & 4:00 pm & Room D/E \\
\hline Pratt, Daniel & *D3.1 & D3: Superconductivity & Tuesday, June 26 & $10: 30 \mathrm{am}$ & Room G \\
\hline Ratcliff, William & *D5.1 & D5: Multiferroics and Complex 0xides & Wednesday, June 27 & $10: 30 \mathrm{am}$ & Room G \\
\hline Roberts, Christopher & *E3.1 & E3: Stability and Dynamics & Wednesday, June 27 & $1: 45 \mathrm{pm}$ & Room 5/6 \\
\hline Seshadri, Ram & ${ }^{\star} \mathrm{F} 2.2$ & F2: Local Structure & Monday, June 25 & $4: 30 \mathrm{pm}$ & Room A/B \\
\hline Tse, John & *G4.1 & G4: Energy Storage Materials & Wednesday, June 27 & $1: 45 \mathrm{pm}$ & Room A/B \\
\hline Wills, Andrew & ${ }^{\star} \mathrm{F} 2.1$ & F2: Local Structure & Monday, June 25 & 4:00 pm & Room A/B \\
\hline Yang, Jihui & *G2.1 & G2: Energy Conversion Materials & Monday, June 25 & $1: 45 \mathrm{pm}$ & Room 5/6 \\
\hline Zarraga, Isidro (Dan) & *E2.1 & E2: Protein Structure and Assocations & Tuesday, June 26 & $1: 45 \mathrm{pm}$ & Room D/E \\
\hline
\end{tabular}




\section{American Conference on Neutron Scattering (ACNS 2012)}

The Conference was held June 24-28 at Georgetown University, along the scenic Potomac River and near the historic Georgetown section of Washington, District of Columbia, close to downtown and adjacent to the famous Chesapeake and Ohio Canal (a National Historic Park). This 6th conference in the series was sponsored by the Neutron Scattering Society of America (NSSA) and hosted by the Center for Neutron Research at the National Institute of Standards and Technology (NIST). By all measures, the meeting can be judged an overwhelming success with more than 380 enthusiastic people in attendance and a notably interesting set of lectures and poster sessions (more than 325 in total) which covered the principle topics of biology, hard and soft condensed matter, chemistry, neutron physics, energy and engineering applications, as well as sources, instrumentation and software. The diversity of scientific disciplines covered attests to the current breadth of applications of neutron scattering studies. (Conference program details, including abstracts of presentations, can be found on line at www.mrs.org/acns-2012 and www.neutronscattering.org.) The success of the Conference was due in large part to the efforts of the organizing committee (chair Julie Borchers and NSSA president Bruce Gaulin), the program committee (co-chairs Nitash Balsara and Stephan Rosenkranz), the local organizing committee (chair Susan Krueger), Materials Research Society conference coordinators (Jackie Mancheas, Debbie Kriss, and Donna Waterson), and also the generous support of: the Neutron Sciences Directorate at Oak Ridge National Laboratory, the Lujan Neutron Scattering Center at Los Alamos National Laboratory, the NIST Center for Neutron Research (NCNR), the National Research Council Canadian Neutron Beam Centre, and the United States Department of Energy, Office of Basic Energy Sciences. Exhibitors from national facilities as well as commercial manufacturers of relevant equipment were represented at the ACNS and provided information about services and products. The commercial vendors included Advanced Design Consulting, Blake Industries, Cryogenic Limited, General Electric Energy (Reuter Stokes), Janis Research Company, the Kurt J. Lesker Company, and Springer publishers.

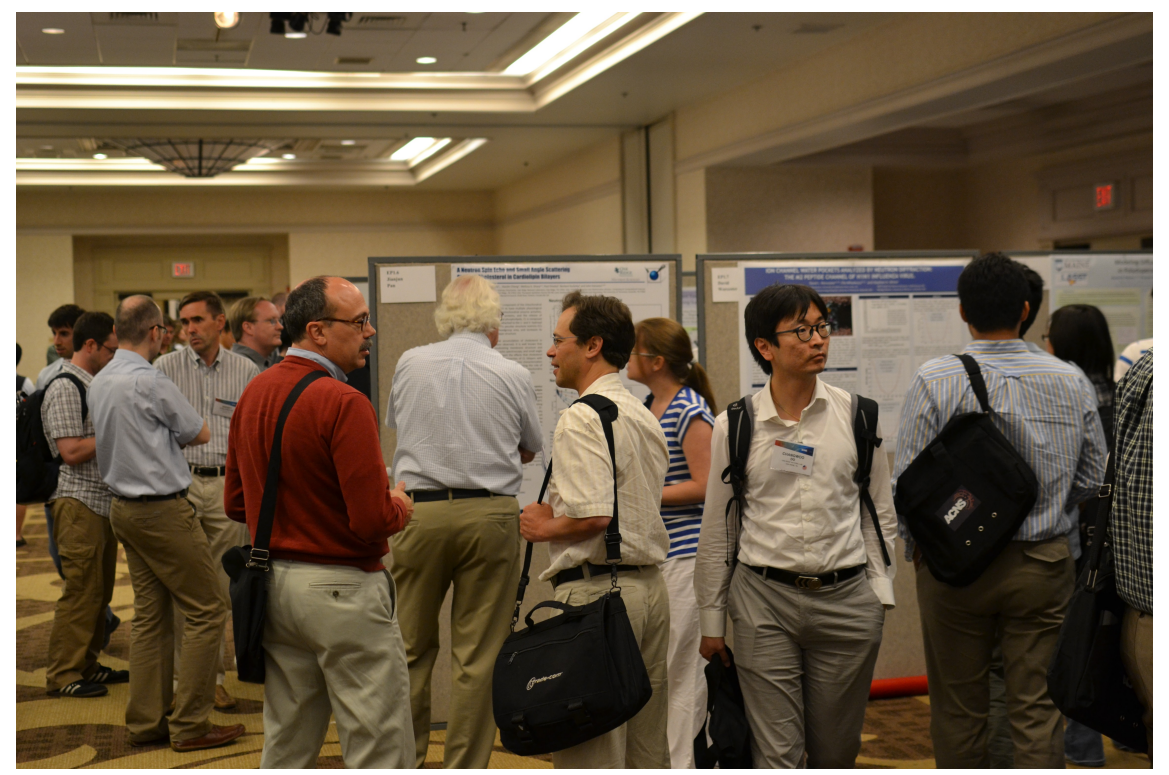

All three poster sessions at the Conference were very heavily attended and a lot of interesting discussion was generated. It is remarkable that neutron scattering methods continue to find an expanding number of applications in a broad range of scientific areas. 
On the Sunday preceding the main program of the Conference, a couple of tutorial sessions were organized. The first dealt with advances in time-of-flight powder diffraction and was chaired by Thomas Proffen of Oak Ridge National Laboratory. The second tutorial focused on novel techniques for small angle neutron scattering and was chaired by Kathryn Krycka of the NIST Center for Neutron Research.

In addition to the scientific program, several awards were presented at the Conference by he NSSA. Guangyong Xu of Brookhaven National Laboratory, Robert J. Birgeneau of the University of California, Berkeley, and Gian Piero Felcher of Argonne National Laboratory, were presented with the Science Prize, Shull Prize, and Sustained Research Prize, respectively. Claire White of Los Alamos National Laboratory received the Outstanding Student Research Prize. More details on these awards are given in an article in Volume 23, Number 2 (April, May, June 2012) of Neutron News. In dedicated sessions, the prize recipients presented lectures about the work for which they had been recognized, except for Gian Felcher who was not able to attend. In his place, Suzanne te Velthuis made a presentation on his behalf. Robert Birgeneau spoke about structural, magnetic, and superconducting transitions in the iron pnictides and chalcogenides while Guangyong Xu described studies probing local polar structures in relaxor ferroelectrics using both neutron and x-ray scattering methods. Suzanne te Velthuis summarized some of Gian Felcher's groundbreaking work on probing surfaces and interfaces with neutron reflectometry. Finally, Claire White talked about recent progress in elucidating accurate structural representations of disordered complex materials. Besides the aforementioned prizes, nine new Fellows of the NSSA were announced, in acknowledgment of their outstanding contributions to neutron scattering and the North American neutron scattering community -- Julie Borchers, Robert Cava, Charles Glinka, Eric Kaler, Roger Pynn, Steven Shapiro, Gregory Smith, Haskell Taub, and Samuel Werner. Congratulations to all of them for this well-deserved recognition.

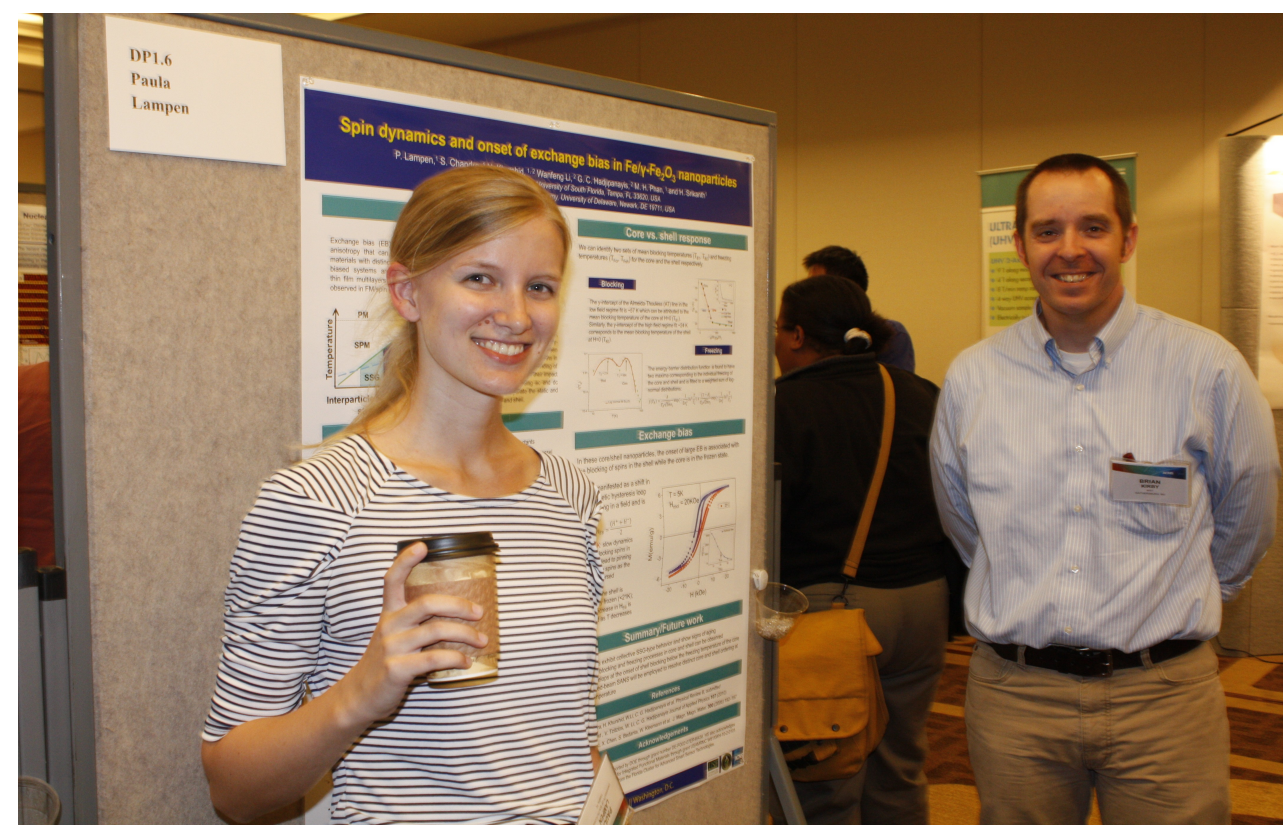

Paula Lampen of the University of South Florida and Brian Kirby of NIST in the midst of discussing magnetic nanoparticles at one of the popular poster sessions. 
At the Conference Banquet on Tuesday evening, two interesting and inspiring talks were presented. The first was given by Sam Werner about the founding of the NSSA, 20 years earlier. He conveyed a sense of the history of the organization, how its membership has increased substantially over the years, and the degree to which it has evolved to become an important proponent of neutron scattering research within the larger scientific community. The second talk was given by Robert Shull, a distinguished senior scientist and Fellow at NIST, who also happens to be the son of Nobel Laureate and pioneering neutron scatterer, the late Clifford Shull. Robert Shull recounted some of the extraordinary science that his father performed with neutrons which ultimately led to, along with the contributions of other early pioneers in the field such as Bert Brockhouse, the establishment of neutron scattering research as an indispensable microscopic probe of condensed matter. Along the way, Dr. Shull also gave us a glimpse of the personal life and times of this great scientist and founding father of our field.

It should also be mentioned that in addition to the well-received invited and contributed oral presentations, as well as the three immensely popular poster sessions, several excellent plenary talks were given. Timothy Lodge of the University of Minnesota spoke about the dynamics of chain exchange in block copolymer micelles and Leon Balents of the University of California, Santa Barbara, talked about quantum spin liquids. From the US Office of Science and Technology Policy, Altaf Carim gave a presentation on federal science and technology policy and initiatives together with the anticipated budget for fiscal year 2013. To complete the series of lectures, Yasuhiko Fujii, gave a very informative talk on the activities of the Asia-Oceania Neutron Scattering Association (AONSA) in his role as president of the organization.

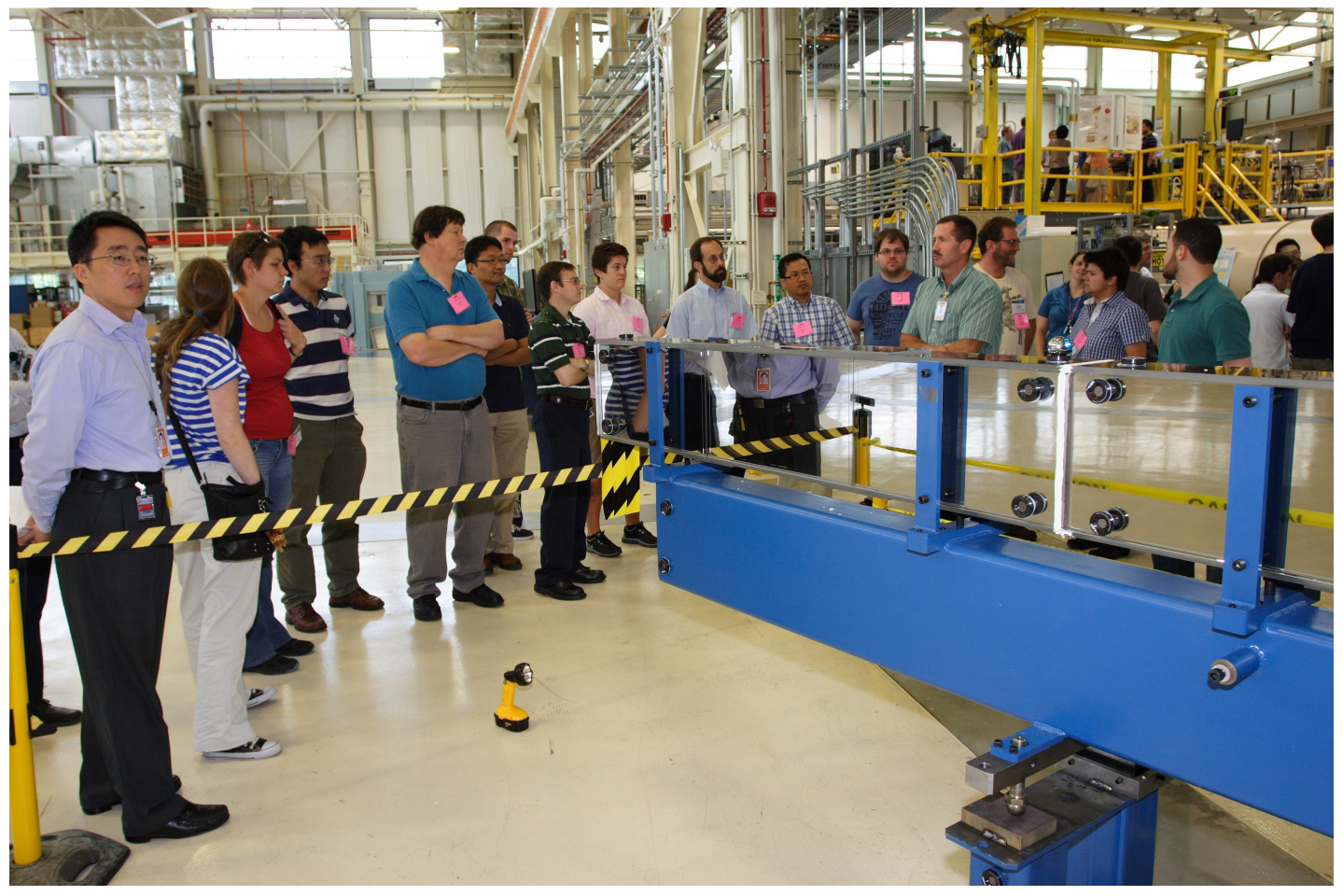

Conference participants join staff members for a tour of the NCNR facility. In the photo above, one of the 5 new guides being installed in the expanded experimental hall is shown in the foreground. 
In addition to the Plenary Sessions each morning, the conference featured four parallel oral sessions during each day followed by a poster session in the late afternoon or evening. The oral sessions were well attended and included invited and contributed talks focused on topics such as "Complex Fluids and Gels" and "Lattice Dynamics." Invited talks ranged from an overview of the structural properties of organogels using rheology, dielectric spectroscopy and Small Angle Neutron Scattering by Danilo Pozzo (University of Washington) to a description of the high-field scattering magnet developments at the National High Magnetic Field Laboratory by Mark Bird. The superconductivity session chaired by Dr. Robert Birgeneau, Shull Prize winner, was particularly dynamic and featured an invited talk by Daniel Pratt (University of Iowa/NIST) on long range magnetic order and excitations in $\mathrm{CaFe}_{2} \mathrm{As}_{2}$.

The Conference culminated on Thursday with a tour of the NIST Center for Neutron Research in Gaithersburg, MD. Visitors were able to see first hand the newly completed guide hall of the NCNR expansion project. After approximately a year-long shut down for this construction, the facility is back up and running as the new guides and instruments are in the process of being installed.

Chuck Majkrzak and Julie Borchers

NIST,

USA 